\title{
SAÚDE BUCAL DO TRABALHADOR E A ASSISTÊNCIA ODONTOLÓGICA NAS EMPRESAS
}

\section{Lucilene Sanches Cirilo da Cunha}

Dissertação apresentada à Faculdade de Odontologia de Bauru, da Universidade de São Paulo como parte dos requisitos para a obtenção do título de Mestre em Odontologia, área de Odontologia em Saúde Coletiva 


\section{SAÚDE BUCAL DO TRABALHADOR E A ASSISTÊNCIA ODONTOLÓGICA NAS EMPRESAS}

\section{Lucilene Sanches Cirilo da Cunha}

Dissertação apresentada à Faculdade de Odontologia de Bauru, da Universidade de São Paulo como parte dos requisitos para a obtenção do título de Mestre em Odontologia, área de Odontologia em Saúde Coletiva

Orientador: Prof. Dr. José Roberto Pereira Lauris 
\begin{tabular}{|c} 
CUNHA, Lucilene Sanches Cirilo da \\
C914s Saúde Bucal do trabalhador e a
\end{tabular}

C914s Saúde Bucal do trabalhador e a assistência odontológica nas empresas. / Lucilene Sanches Cirilo da Cunha. - Bauru, 2005.

87 p.:il.; $29,5 \mathrm{~cm}$.

Dissertação (Mestrado) - Faculdade de Odontologia de Bauru. USP.

Orientador: Prof. Dr. José Roberto Pereira Lauris

Autorizo, exclusivamente para fins acadêmicos e científicos, a reprodução total ou parcial desta dissertação/tese, por processos fotocopiadores e outros meios eletrônicos.

Assinatura:

Data de Aprovação pelo Comitê de Ética em Pesquisa da FOB:

05 de abril de 2004.

A cópia do parecer de aprovação encontra-se no final do capítulo

“Anexos”. 


\section{Lucilene Sanches Cirilo da Cunha}

26 de dezembro de 1977

Bariri-SP

$1997-2001$

2001

2001-2003

2003-2005
Nascimento

Curso de Graduação em Odontologia Faculdade de Odontologia do Sagrado Coração de Jesus - USC - Bauru-SP.

Curso de Aperfeiçoamento em Odontologia em Saúde Coletiva, pela Associação Paulista de CirurgiõesDentistas - APCD -Bauru, SP.

Curso de Especialização em Odontologia em Saúde Coletiva, pelo Hospital de Reabilitação de Anomalias Craniofaciais - HRAC Bauru, SP.

Curso de Pós-Graduação em Odontologia em Saúde Coletiva, ao nível de Mestrado, na Faculdade de Odontologia de Bauru da Universidade de São Paulo. 
CROSP - Conselho Regional de

Odontologia de São Paulo

APCD - Associação Paulista de Cirurgiões-

Dentistas

ABRASCO - Associação Brasileira de Pós-

Graduação em Saúde Coletiva

SBPqO - Sociedade Brasileira de Pesquisas

Odontológicas 


\title{
DEDICATÓRIA
}

\author{
À Deus \\ “Porque dEle e por Ele e para Ele são todas as coisas”. Rm11:36
}

\begin{abstract}
À minha família
Clara, Marlene, José Luiz, Maria Dolores, Doraci e todos que nos cercam.

Que de um modo todo especial, acompanham minha caminhada, com carinho, incentivo e dedicação, sorrindo e chorando comigo. Meu reconhecimento e gratidão por tudo que fizeram por mim.
\end{abstract}

Ao meu marido, Cássio Rogério da Cunha

Que compreende meus esforços na busca de um futuro melhor e apóia, com amor, minhas decisões . 


\section{AGRADECIMENTOS ESPECIAIS}

Ao meu orientador,

Prof. Dr. José Roberto Pereira Lauris,

Pelo exemplo de competência e simplicidade ao mesmo tempo, pelos ensinamentos e orientação deste trabalho, a quem cultivo além de gratidão, respeito e admiração.

Ao coordenador do Curso de Mestrado,

Prof. Dr. José Roberto de Magalhães Bastos,

Pelo constante estímulo à carreira acadêmica e realização deste curso, obrigada pela oportunidade. Certamente me lembrarei dos seus conselhos.

À amiga

Renata de Almeida Pernambuco,

Presente em todos os momentos, sempre me incentivou com alegria. Agradeço toda ajuda, apoio e exemplo que você me ofereceu. 
AGRADECIMENTOS

AO DEPARTAMENTO DE ODONTOLOGIA EM SAÚDE COLETIVA

Aos Professores:

Arsenio Salles Peres, Silvia Helena de Carvalho Salles Peres e Nilce Emy Tomita;

Às funcionárias:

Marta, Helena, Silvia e Rosa

Sincera gratidão a todos, pelos ensinamentos e convívio durante o curso de Mestrado.

Aos meus colegas de mestrado:

Hilton, Haroldo, Aline, Beatriz, Irene, Roberta e Ricardo. Obrigada por compartilhar conhecimentos e momentos importantes comigo.

Especialmente à Fabíola, Kelly e Priscila, obrigada por estarem sempre prontas a me ouvirem se revelando verdadeiras amigas e companheiras nesta jornada. 
Aos colegas:

Sheyne e Adelson que, prontamente, participaram da coleta de dados.

\section{Às EMPRESAS}

Que participaram gentilmente deste estudo. Obrigada pela recepção e atenção com que fomos recebidos. 


\section{SUMÁRIO}

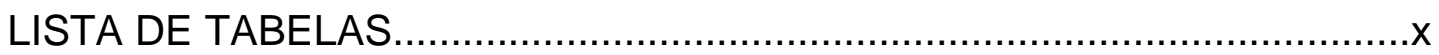

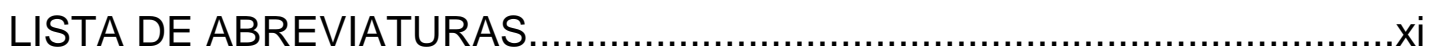

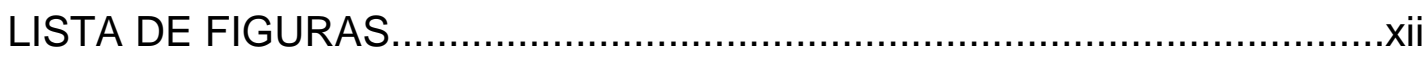

LISTA DE QUADROS...........................................................................

RESUMO

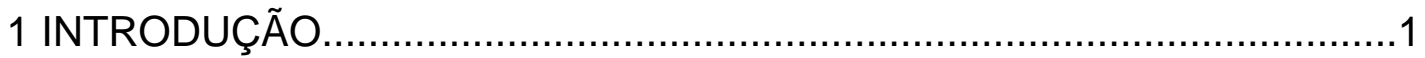

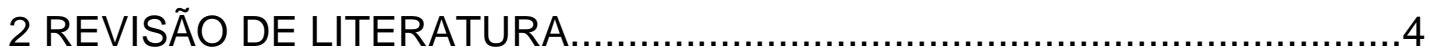

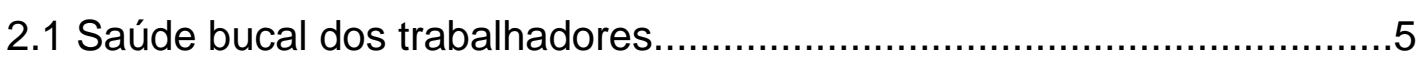

2.2 Absenteísmo odontológico.............................................................16

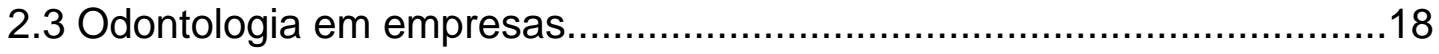

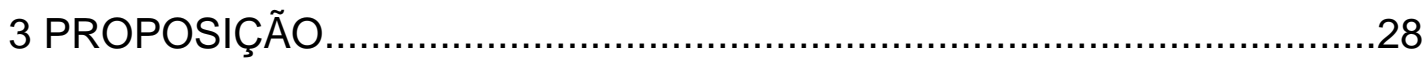

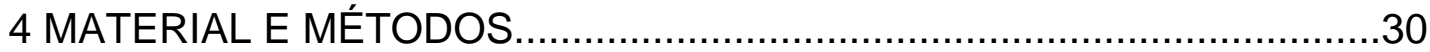

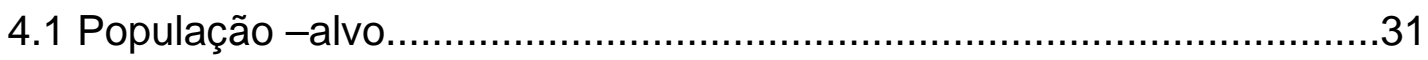

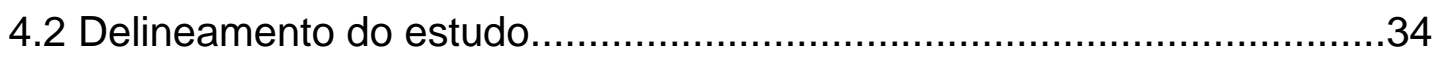

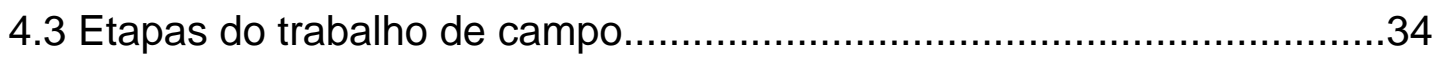

5 RESULTADOS

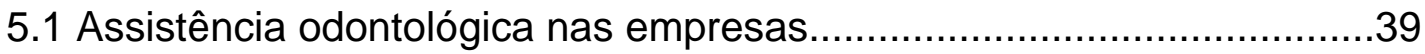

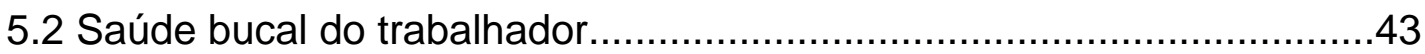

6 DISCUSSÃO

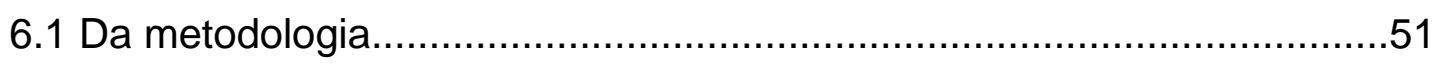

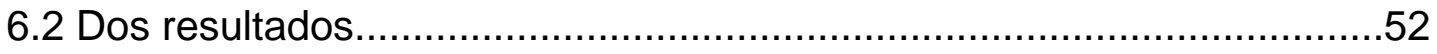

7 CONCLUSÃO

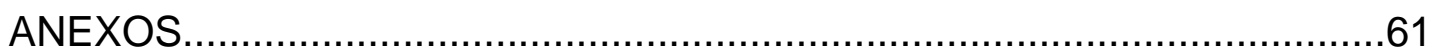

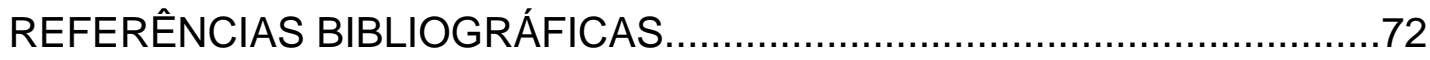

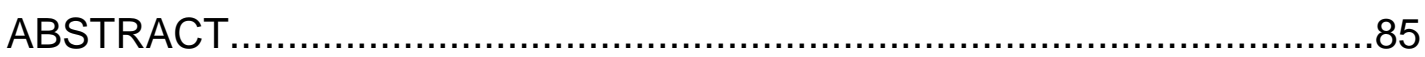




\section{LISTA DE TABELAS}

TABELA 1 - Descrição das DIRs de acordo com a cidade, 2004.

TABELA 2 - Porte da empresa de acordo com critério do CIESP, 2004.

TABELA 3 - Municípios da DIR X, com respectivo número de empresas de grande porte, 2004

TABELA 4 - Distribuição da amostra segundo o tipo de assistência odontológica desenvolvida em empresas de grande porte da DIR X, 2004

TABELA 5 - Número médio de dentes encontrados nos trabalhadores de acordo com o gênero, 2004

TABELA 6 - Condição protética da arcada superior de trabalhadores de acordo com o gênero, 2004

TABELA 7 - Condição protética da arcada inferior de trabalhadores de acordo com o gênero, 2004

TABELA 8 - Necessidade protética da arcada superior de trabalhadores de acordo com o gênero, 2004.

TABELA 9 - Necessidade protética da arcada inferior de trabalhadores de acordo com o gênero, 2004. 


\section{LISTA DE ABREVIATURAS}

$\begin{array}{ll}\text { CD } & \text { Cirurgião-dentista } \\ \text { CID } & \text { Classificação Internacional de Doenças } \\ \text { CIESP } & \text { Centro de Indústrias do Estado de São Paulo } \\ \text { CIPA } & \text { Comissão Interna de Prevenção de Acidentes } \\ \text { CNAE } & \text { Código Nacional de Atividade Econômica } \\ \text { CPOD } & \text { Índice de dentes cariados, perdidos e obturados } \\ \text { FDI } & \text { Federação Dentária Internacional } \\ \text { OMS } & \text { Organização Mundial da Saúde } \\ \text { PPF } & \text { Prótese Parcial Fixa } \\ \text { PPR } & \text { Prótese Parcial Removível } \\ \text { PT } & \text { Prótese Total }\end{array}$




\section{LISTA DE FIGURAS}

FIGURA 1 - Mapa com os 38 municípios pertencentes à DIR X, 2004........

FIGURA 2 - Descrição da amostra de funcionários examinados, de acordo com o gênero, 2004.

FIGURA 3 - Número médio de dentes encontrados em trabalhadores, de acordo com o gênero e com desvio padrão, Bauru, 2004........

FIGURA 4 - Condição protética da arcada superior de trabalhadores de acordo com o gênero, 2004.

FIGURA 5 - Condição protética da arcada inferior de trabalhadores de acordo com o gênero, 2004.

FIGURA 6 - Necessidade protética da arcada superior de trabalhadores de acordo com o gênero, 2004.

FIGURA 7 - Necessidade protética da arcada inferior de trabalhadores de acordo com o gênero, 2004. 


\section{LISTA DE QUADROS}

QUADRO 1 - Doenças do sistema digestivo relacionadas como trabalho, 1999

QUADRO 2 - Comparação entre as metas propostas pela OMS / FDI para o ano de 2000 com relação à cárie dentária e os resultados do Projeto SB Brasil, 2003. 
RESUMO 


\section{RESUMO}

A atenção à Saúde Bucal deve ser direcionada a todas as faixas etárias e populações específicas. É possível observar com facilidade programas preventivos desenvolvidos para crianças, gestantes, idosos, e com menor freqüência enfocando a população adulta. Na busca de direcionar esforços para a melhoria da saúde bucal do trabalhador foi delineado este estudo com o objetivo de verificar a existência e o tipo de assistência odontológica oferecida por empresas de grande porte na região centro-oeste do Estado de São Paulo, assim como verificar a condição de saúde bucal de trabalhadores com idade de 35 a 44 anos. Em uma primeira fase ocorreu entrevista no setor administrativo de 17 empresas. Após, foram realizados exames bucais em 100 funcionários de uma empresa que consentiu em participar desta etapa. Os resultados demonstraram que $85,71 \%$ das empresas pesquisadas ofereciam assistência odontológica, sendo o tipo predominante convênio com CD em consultório particular e reembolso de $50 \%$ do valor do tratamento. A média de dentes presentes foi de 23,61 para os homens e 19,43 para as mulheres, sendo que cerca de $70 \%$ apresentavam 20 ou mais dentes em condições funcionais, se aproximando da meta da OMS para o ano de 2000. Conclui-se que a assistência odontológica para os funcionários é oferecida como benefício pela maioria das empresas da DIR 10. Manobras que visem à melhoria das condições de saúde bucal dos trabalhadores são necessárias, buscando atingir níveis compatíveis com as metas propostas pela Organização Mundial da Saúde. 
1 INTRODUÇÃO 


\section{INTRODUÇÃO}

O atual perfil da odontologia preocupa-se com a prevenção trazendo uma concepção de saúde bucal não somente de dentes preservados, mas sim de qualidade de vida. Desta forma a atenção à Saúde Bucal deve ser direcionada a todas as faixas etárias e populações específicas. É possível observarmos com facilidade programas preventivos enfocando crianças, gestantes, idosos, porém com relação à população adulta isto se torna mais difícil.

Com relação aos trabalhadores, a maioria apresenta uma carga horária de trabalho que dificulta a procura de serviços tradicionais de saúde, quer públicos ou privados, além de existir uma resistência dos empresários em facilitar saídas e ausências mesmo por motivo de saúde ${ }^{56}$. Portanto pode-se enumerar várias justificativas em favor da implantação de serviços e benefícios odontológicos nas empresas.

Os benefícios, que podem ser elencados a partir da inserção do cirurgião-dentista na equipe de Saúde do Trabalhador, vão desde o aprendizado dos cuidados com a higiene bucal, aumento da motivação do trabalhador e da imagem da empresa perante o mesmo, até a facilidade de acesso aos cuidados odontológicos, tratamento das doenças bucais, eliminação dos focos de infecção e das dores de origem dentária, que é uma das principais causas de acidentes de trabalho ${ }^{40}$. 
A própria empresa também se beneficiará com esta inclusão, pois os índices de absenteísmo serão diminuídos, a imagem da empresa no mercado será melhor, haverá maior produtividade individual, diminuição das possibilidades de acidentes de trabalho e doenças profissionais com manifestações bucais, além do que, é possível abater as despesas com os serviços odontológicos na Declaração do Imposto de Renda.

Quando se discute as incapacidades que atingem os trabalhadores não podemos excluir as doenças bucais, pois estas não se desvinculam das condições gerais de saúde do corpo $^{27}$. Portanto qualquer problema de origem bucal pode provocar desconforto físico, emocional, prejuízos consideráveis a saúde geral, além de diminuir a produtividade de um empregado dentro de sua função ${ }^{23}$.

Têm sido observados altos índices de cárie e periodontopatias em adultos, enfatizando a necessidade de se facilitar o acesso desta população aos serviços de atenção à saúde bucal. Diante disto este trabalho se propõe a analisar a existência e o tipo de assistência odontológica oferecida por empresas de grande porte, visto que estas são as que oferecem mais benefícios aos seus funcionários, pertencentes aos municípios que compõe a Divisão Regional de Saúde (DIR-X), além de verificar o uso e satisfação do funcionário diante do benefício oferecido e sua condição de Saúde Bucal. 
2 REVISÃO DE LITERATURA 


\section{REVISÃO DE LITERATURA}

\subsection{Saúde Bucal dos trabalhadores}

O conceito de Saúde Bucal passou por algumas alterações no decorrer do tempo que dividiu e norteou a própria prática odontológica. Do início do século até a década de sessenta a Odontologia se encontrava num estágio radical, onde o objetivo era o alívio das dores por meio das extrações, na década de setenta a Odontologia curativa se destacou, neste período ter saúde bucal era o dente estar restaurado. Atualmente atentando para os aspectos biológicos das doenças bucais, motiva-se o indivíduo para que cuide de sua boca, investindo na prevenção. As concepções de saúde bucal se modificaram, mas é certo que qualidade de vida não existe quando a saúde bucal está comprometida (NARVAl ${ }^{47}$, 1994; FERREIRA ${ }^{23}, 1997$; MENDONÇA ${ }^{39}$, 2001).

Muitos estudos têm sido conduzidos enfocando a saúde bucal de trabalhadores, e aspectos nocivos de sua atividade laboral. A importância do cirurgião-dentista na equipe de saúde do trabalhador é destacada desde 1972 por NOGUEIRA ${ }^{49}$, que descreve diversos quadros patológicos bucais decorrentes de doenças profissionais ocasionados por agentes mecânicos, físicos, químicos e biológicos. 
Em 1999, a saúde bucal do trabalhador foi destacada como um novo campo de atuação profissional para o CD (ARAÚJO, JÚNIOR³). Os autores relataram que este novo campo deveria abordar a epidemiologia e patologia das doenças ocupacionais, buscando prevenir os efeitos nocivos das condições de trabalho e suas influências sobre a saúde. As condições de trabalho interferem na qualidade de saúde bucal dos trabalhadores e alterações na mucosa permitem muitas vezes um diagnóstico precoce de envolvimento sistêmico.

Existe uma série de situações nas quais ocorrem manifestações bucais em razão da ação de agentes químicos, responsáveis pela maioria das doenças ocupacionais (QUADRO 1). ESTEVES ${ }^{19}$, em 1982 com o propósito de alertar o médico do trabalho para a necessidade da realização de exames minuciosos da cavidade bucal dos trabalhadores, realizou um estudo para que possam ser detectadas no ambiente de trabalho patologias bucodentárias decorrentes ou não das atividades profissionais, para que desta forma providências sejam tomadas no sentido de minimizar problemas odontológicos. 
QUADRO 1 - Relação de doenças do sistema digestivo e sua relação com agentes ou fatores de risco de natureza ocupacional, 1999.

DOENÇAS DO SISTEMA DIGESTIVO RELACIONADAS COM O TRABALHO (Grupo XI da CID-10)

\begin{tabular}{|c|c|}
\hline DOENÇAS & $\begin{array}{c}\text { AGENTES ETIOLÓGICOS OU } \\
\text { FATORES DE RISCO DE NATUREZA } \\
\text { OCUPACIONAL }\end{array}$ \\
\hline Erosão Dentária (K03.2) & $\begin{array}{l}\text { - Névoas de fluoretos ou seus } \\
\text { compostos tóxicos } \\
\text { - Exposição ocupacional a outras } \\
\text { névoas ácidas }\end{array}$ \\
\hline $\begin{array}{l}\text { Alterações pós-eruptivas da cor dos } \\
\text { tecidos duros dos dentes (K03.7) }\end{array}$ & $\begin{array}{l}\text { - Névoas de Cádmio ou seus } \\
\text { compostos } \\
\text { - Exposição ocupacional a metais: } \\
\text { cobre, níquel, prata }\end{array}$ \\
\hline Gengivite Crônica (K05.1) & $\begin{array}{l}\text { - } \begin{array}{l}\text { Mercúrio e seus compostos } \\
\text { tóxicos }\end{array} \\
\end{array}$ \\
\hline Estomatite Ulcerativa Crônica (K12.1) & $\begin{array}{llll}\text { - } & \text { Arsênio e seus compostos } \\
\text { arsenicais } & & \\
\text { - } & \text { Bromo } \\
\text { - } & \text { Mercúrio e seus compostos } \\
\text { tóxicos }\end{array}$ \\
\hline Gastroenterite e Colite tóxicas (K52.-) & $\begin{array}{l}\text { - Arsênio e seus compostos } \\
\text { arsenicais } \\
\text { - Cádmio ou seus compostos } \\
\text { - Radiações ionizantes }\end{array}$ \\
\hline $\begin{array}{l}\text { Outros transtornos funcionais do } \\
\text { intestino ("Síndrome dolorosa abdominal } \\
\text { paroxística apirética, com estado } \\
\text { suboclusivo "cólica do chumbo") (K59.8) }\end{array}$ & - Chumbo e seus compostos \\
\hline $\begin{array}{l}\text { Doença Tóxica do Fígado (K71.-): } \\
\text { Doença Tóxica do Fígado, com Necrose } \\
\text { Hepática (K71.1); com Hepatite Aguda } \\
\text { (K71.2); com Hepatite Crônica } \\
\text { Persistente(K71.3); com outros } \\
\text { transtornos Hepáticos (K71.8) }\end{array}$ & $\begin{array}{l}\text { - Cloreto de Vinila, Clorobenzeno, } \\
\text { Tetracloreto de Carbono, } \\
\text { Clorofórmio e outros solventes } \\
\text { halogenados hepatotóxicos } \\
\text { - Hexaclorobenzeno } \\
\text { - } \text { Bifenilas policloradas } \\
\text { - Tetraclorodibenzodioxina }\end{array}$ \\
\hline Hipertensão Portal (K76.6) & $\begin{array}{ll}\text { - } & \text { Arsênio e seus compostos } \\
& \text { arsenicais } \\
\text { - Cloreto de vinila } & \\
\text { - } & \text { Tório } \\
\end{array}$ \\
\hline
\end{tabular}

Fonte: BRASIL ${ }^{8}$, Ministério da Saúde, Portaria 1.339, de 18 de dez. de 1999. 
Para avaliar alguns hábitos de higiene bucal, ABEGG ${ }^{1}$ (1997), selecionou em 18 empresas de Porto Alegre uma amostra por conveniência de 234 mulheres e 237 homens que responderam um questionário. Foi possível identificar que a freqüência de escovação é cerca de 3 vezes ao dia, a maioria dos entrevistados $(67,5 \%)$ declarou usar fio dental, o uso do palito também se mostrou comum (54,6\%). Porém na mesma amostra foram encontrados altos níveis de placa bacteriana e sangramento gengival, havendo necessidade de melhoria da higienização principalmente para os homens e pessoas de categoria sócio-econômica inferior.

Também estudando a higiene bucal em adultos, BOTINO, MOREIRA e ROSSETINI ${ }^{6}$ (1982), propuseram um programa de educação em saúde bucal composto de informações sobre saúde bucal e instrução de escovação. Os resultados obtidos foram satisfatórios, demonstrando redução de placa dentária em pacientes adultos necessitando de prótese parcial em cerca de 70\%. O número de sessões de instrução e treinamento poderia ser fixado em 5 consecutivas, pois $85 \%$ dos pacientes mantiveram os resultados obtidos na $5^{\mathrm{a}}$ sessão até o final do tratamento.

Analisando as condições dentárias de trabalhadores de uma indústria cerâmica, FERRAZ, BELINI ${ }^{21}$ (1983) verificaram que a média de dentes presentes em adultos com idade entre $35-44$ foi de 14,8 , cerca de 21\% apresentavam-se desdentados superior ou inferior, porém fazendo uso de prótese. Do total dos trabalhadores, 6,6\% eram desdentados totais sendo que todos apresentavam próteses. Após os 35 anos de idade o tratamento mais freqüente, nesta indústria cerâmica pesquisada, foi prótese total. A 
amostra foi composta de indivíduos do sexo masculino devido ao tipo de trabalho desenvolvido na indústria, em geral pesado.

Como muitas doenças sistêmicas apresentam manifestações bucais, HOLLISTER, WEINTRAUB ${ }^{32}$, em 1993, realizaram um estudo buscando associar o estado de saúde bucal com a saúde sistêmica, qualidade de vida e produtividade econômica. Os resultados demonstraram que as condições de saúde bucal exercem influência direta na saúde sistêmica e qualidade de vida da população, assim como na produtividade econômica, ressaltando que as patologias bucais são responsáveis pela perda de muitos dias de trabalho.

Ainda assim estudos epidemiológicos, como o realizado por $\mathrm{DINI}^{16}$, demonstram alta prevalência da doença periodontal na população adulta. Em 1995, este autor avaliou a condição de saúde bucal de 528 trabalhadores de usinas de álcool e açúcar, com idade variando de 18 a 64 anos. Os exames clínicos foram realizados por uma única examinadora e os resultados demonstram associação positiva e estatisticamente significante entre a presença de placa, bolsas periodontais e uso de prótese dental, sendo que $88,7 \%$ dos usuários de prótese apresentavam prótese parcial removível.

PETERSEN et al. ${ }^{53}$ em 1997, verificaram as condições de saúde bucal de trabalhadores na Romênia, de acordo com critérios da OMS. Constataram que nos grupos mais jovens a quantidade de cárie dentária não tratada era alta, enquanto que nos trabalhadores mais velhos predominava a 
quantidade de dentes extraídos. O estudo enfatiza a necessidade de reorientar os cuidados com saúde bucal, e a importância da assistência odontológica na prevenção e promoção de saúde em adultos.

Com relação à doença cárie dentária, também nota-se alto índice da doença, o número de dentes comprometidos chega a 15,53 (TOMITA et al. ${ }^{70}, 1999$ ), nesse mesmo estudo com 156 trabalhadores, foi possível observar em relação à doença periodontal que 17\% apresentavam cálculo, $60 \%$ tinham bolsa periodontal de $4-5 \mathrm{~mm}$ e $23 \%$ a profundidade da bolsa era maior de $6 \mathrm{~mm}$.

Algumas patologias bucais preveníveis, como cárie e doença periodontal alcançam níveis elevados no Brasil, conduzindo a perdas dentárias totais em cerca de 33,3\% dos indivíduos na faixa etária dos 25 anos (TOMITA, BASTOS, BASSANI $\left.{ }^{71} ; 1992\right)$.

DOUGHAN, KASSAK, BOURGEOIS ${ }^{17}$, conduziram um estudo em 2000, onde foram avaliadas as condições de saúde bucal em uma população de 401 adultos com idade variando de 35 a 44 anos. Utilizando metodologia da OMS foi possível encontrar um índice CPOD de 16,3, e uso de prótese removível em 16\% da amostra. Este estudo serviu de base para o conhecimento da saúde bucal desta população, e possivelmente orientará ações e estratégias para melhora dos índices de saúde bucal.

A perda dos dentes é considerada como decorrência das doenças bucais mais prevalentes, cárie e doença periodontal 
(MENDONÇA $^{39}$, 2001). Alto percentual de perda dentária e uso e necessidade de prótese também foi verificado por CANGUSSU, COELHO e CASTELHANOS ${ }^{11}$ (2001), em estudo onde observaram as condições de saúde bucal de adultos na faixa etária de 35-44 anos e acima de 65, no município de Itatiba/SP. O CPOD encontrado foi respectivamente 21,01 e 28,14; a proporção de indivíduos sadios em relação à doença periodontal foi praticamente nula, o que levou os autores a concluírem que é necessário facilitar o acesso aos serviços de saúde bucal para adultos.

Em estudo sobre a perda de estrutura dentária causada por ácidos sem envolvimento de bactérias, num grupo de 68 trabalhadores de fábrica de baterias na Jordânia, AMIN; AL-OMOUSH e HATTAB², em 2001, verificaram que indivíduos expostos à gases ácidos no ambiente de trabalho apresentam erosão dental e piores condições de saúde bucal. Apontando desta forma a necessidade de medidas educativas e preventivas juntamente com um eficiente programa de inspeção e monitoramento do ambiente de trabalho, além da instalação de serviços de atenção médica e odontológica.

VIANNA e SANTANA ${ }^{72}$, em 2001, estudaram a exposição ocupacional a névoas ácidas e alterações bucais. Encontraram associação positiva entre névoa ácida e erosão dental, com relação à doença periodontal e lesões na mucosa bucal os estudos são mais recentes e apresentam-se controversos. A saúde bucal foi ressaltada como fator importante e deve ser englobada em programas de saúde do trabalhador. 
As condições de saúde bucal na população adulta nem sempre se encontra em bons níveis porque, de acordo com GARCIA et $a^{26}$. em 2001, a higiene bucal dos adultos deve ser melhorada, pois poucos pacientes demonstraram ter uma higiene bucal totalmente satisfatória. Em estudo que avaliou o comportamento de 61 adultos que eram atendidos em serviço público do município de São Carlos-SP, foram feitas observações clínicas da higiene bucal demonstrada pelo paciente, no que diz respeito à técnica de escovação. Os resultados mostraram que $75,4 \%$ da população estudada passavam o fio dental antes da escovação, porém somente 27,9\% utilizavam a técnica corretamente. A respeito da escovação, 65,65\% realizavam incorretamente, sendo a escova dentária apresentada em bom estado por $59 \%$.

BRANT e MELO (2001), relacionaram desafios da articulação entre promoção de saúde e trabalho, reforçando que devem existir combinações de estratégias, ou seja, tanto o Estado como a comunidade, sistemas de saúde e o próprio indivíduo devem agir concomitantemente, com a idéia de responsabilidade múltipla.

O mercado de trabalho se apresenta cada vez mais exigente, o trabalhador se depara constantemente com o estresse da instabilidade, pois as empresas têm a necessidade de profissionais polivalentes, instruídos e com iniciativa. As condições de trabalho muitas vezes apresentam relação como o adoecimento dos trabalhadores. Porém a relação saúde e trabalho não diz respeito apenas ao adoecimento, mas aos acidentes e ao 
sofrimento, e ao fato de que a saúde deve ser construída também no ambiente de trabalho (ASSUNÇÃO $\left.{ }^{5}, 2003\right)$.

Com o mesmo enfoque SILVA, JUNIOR, SANTANA ${ }^{63}$, também em 2003 descrevem que o novo padrão mundial de produção e comércio tem produzido mudanças no mundo de trabalho, nos determinantes da saúde-doença e na organização das práticas de saúde e de segurança no trabalho. Os agravos à saúde dos trabalhadores englobam, além dos acidentes de trabalho, as doenças profissionais, que apresentam relação nítida com o trabalho, e as doenças relacionadas ao trabalho, diferentemente da primeira citada aqui o trabalho é assumido como co-fator na etiologia da doença.

Os levantamentos em saúde bucal fornecem uma base para as estimativas das condições atuais de saúde bucal de uma população, bem como suas futuras necessidades quanto aos cuidados bucais. Os dados produzidos nos levantamentos orientam o planejamento de tratamentos, além de serem úteis no monitoramento das alterações nos níveis e padrões de doenças e na avaliação dos serviços (OMS $\left.{ }^{52}, 1999\right)$.

O Ministério da Saúde ${ }^{43}$ (2003) realizou um levantamento epidemiológico em 127.939 pessoas nas diferentes regiões do país, que avaliou os principais agravos em diferentes grupos etários, incluindo a população urbana e rural, identificado hoje como "SB Brasil - Condições de Saúde Bucal na População Brasileira". Foram observadas várias características relativas à saúde bucal, entre elas uso e necessidade de 
prótese. Sendo 13.431 pessoas na idade de 35-44 anos, foi possível observar que com relação à doença cárie dentária os valores encontrados se apresentam altos, $C P O D=20,13$. Comparando os resultados obtidos com as metas da OMS e FDI para o ano de 2000 (QUADRO 2), somente aos 12 anos as metas foram atingidas para as outras idades os níveis estão aquém, sendo que em adultos e idosos o ataque de cárie e o número de dentes perdidos são profundamente elevados. A perda dentária precoce é grave e a necessidade de algum tipo de prótese começa a surgir a partir da faixa etária de 15 a 19 anos, na idade de 35 a 44 anos o uso e a necessidade de próteses estão demonstradas em tabelas (Anexo 1 e 2). No que diz respeito ao acesso ao tratamento odontológico, cerca de $46 \%$ dos adultos vão ao dentista devido a presença de dor, a maioria recebe atendimento em Serviço Público e 64,94\% consideram o atendimento bom. 
QUADRO 2 - Comparação entre as metas propostas pela OMS / FDI para o ano de 2000 com relação à cárie dentária e os resultados do Projeto SB Brasil, 2003.

\begin{tabular}{|c|c|c|}
\hline IDADE & METAS DA OMS 2000 & BRASIL 2003 \\
\hline 5 a 6 anos & $50 \%$ livres de cárie & $\begin{array}{c}40,62 \% \text { livres de } \\
\text { cárie }\end{array}$ \\
\hline 12 anos & CPO-D menor que 3,0 & CPO-D $=2,78$ \\
\hline 18 anos & $\begin{array}{c}80 \% \text { com P=O (todos os dentes } \\
\text { permanentes na boca) }\end{array}$ & $55,09 \% \mathrm{P}=0$ \\
\hline $\begin{array}{c}35 \text { a } 44 \\
\text { anos }\end{array}$ & $\begin{array}{c}75 \% \text { com } 20 \text { ou mais dentes } \\
\text { presentes na boca }\end{array}$ & $53,96 \%$ \\
\hline $\begin{array}{c}65 \text { a } 74 \\
\text { anos }\end{array}$ & $\begin{array}{c}50 \% \text { com } 20 \text { ou mais dentes } \\
\text { presentes na boca }\end{array}$ & $10,23 \%$ \\
\hline
\end{tabular}

Fonte: Ministério da Saúde ${ }^{43}$, Projeto SB Brasil, 2003.

As metas apresentadas na comparação são para o ano de 2000, e foram ampliadas para o ano de 2010, sendo que para a faixa etária de interesse de 35 a 44 anos, a meta consiste em que $90 \%$ destas pessoas tenham 20 ou mais dentes na cavidade bucal e que o índice de desdentados não ultrapasse $2 \%\left(\mathrm{FDI}^{20}, 1982\right)$.

FRAZÃO, ANTUNES, NARVAl ${ }^{25}$ (2003), analisaram o ataque de cárie de acordo com critérios da OMS em exames epidemiológicos de professores e funcionários de escolas públicas e particulares. O índice CPOD apresentou-se elevado (22,39), indicadores sócio-econômicos 
municipais mostraram correlação com a proporção de adultos com ao menos 20 dentes funcionais.

MATOS et al. ${ }^{35}$ em 2002, estudaram os serviços odontológicos públicos, privados e de sindicatos, entrevistando adultos da cidade de Bambuí, no estado de Minas Gerais. Verificaram que tanto os usuários de serviço privado quanto os de sindicato estavam mais satisfeitos com a aparência dos dentes e mastigação do que os usuários do serviço público, além disso também receberam mais tratamento restaurador e preventivo. Portanto os serviços públicos odontológicos não têm conseguido reduzir as desigualdades sociais com referência à saúde bucal. Na busca de contribuir para que esse cenário seja revertido, minimizando as desigualdades é necessária uma reflexão do direito à saúde (NOGUEIRA, PIRES; 2004).

\subsection{Absenteísmo Odontológico}

Absenteísmo é a falta do funcionário ao dia de trabalho, ou ainda quando existe a diminuição de atenção no trabalho, por motivo de dor ou mal estar o funcionário não consegue desempenhar de maneira satisfatória sua função, também chamado de Absenteísmo de corpo presente (FERREIRA $\left.{ }^{22}, 1995\right)$.

“Não existem valores palpáveis para aferirmos o número de dias perdidos de trabalho por razões de absenteísmo odontológico. Não existem portanto, informações tanto a respeito do ônus econômico que tais faltas possam acarretar, como também no nível de insatisfação do 
trabalhador pela quebra do binômio saúde-trabalho" (SÁ LIMA $\left.{ }^{59}, 2001\right)$. Já outros autores conferem à cárie e outras complicações bucais a responsabilidade de $20 \%$ das faltas ao serviço e queda de produção (FERREIRA $\left.{ }^{22}, 1995\right)$.

THOMAS $^{69}$, desde 1943 afirma que existe uma perda financeira muito grande nas indústrias devido doença e acidentes. Empresas com mais de 500 funcionários deveriam manter uma equipe de higiene e segurança no trabalho, pois o desperdício de força humana através de acidentes e doenças é intolerável, pois estes podem ser prevenidos a baixos custos.

Em relação aos acidentes de trabalho, PIMENTEL ${ }^{57}(1976)$

relatou que cerca de $77 \%$ dos homens envolvidos nestes acidentes apresentavam problemas dentários, e ressaltou que a presença do cirurgiãodentista dentro da indústria seria a única maneira de equilibrar dois interesses: o bem estar do funcionário e o desenvolvimento normal da produção.

DIACOV e SÁ LIMA ${ }^{15}$ (1988) após estudarem 7.012 casos de absenteísmo odontológico em trabalhadores da Prefeitura Municipal de São José dos Campos, concluíram que o maior índice de absenteísmo ocorreu na faixa etária de 20 a 30 anos, nos trabalhadores do sexo masculino que exerciam função burocrática, e ainda que quando aumenta a faixa etária diminui o índice de absenteísmo por causas odontológicas. 
O máximo da capacidade produtiva da população trabalhadora será desempenhada quando esta estiver satisfeita com suas necessidades básicas de saúde (SÁ LIMA $\left.{ }^{59}, 2001\right)$.

\subsection{Odontologia em empresas}

"Não há duvidas quanto à importância de uma prática odontológica que contemple a saúde bucal coletiva, universalizando o acesso e garantindo equidade no atendimento das necessidades da população" (PETRY, VICTORA, SANTOS $\left.{ }^{54}, 2000\right)$.

Algumas empresas têm enfocado qualidade, e como reflexo disto disponibilizam aos trabalhadores, assistência odontológica (DePORTER ${ }^{14}$, 1997). Vários autores abaixo, elencam benefícios da presença do cirurgião-dentista na empresa enfocando a Saúde do Trabalhador.

Inicialmente os benefícios atingem diretamente o próprio trabalhador:

- Facilidade de acesso aos cuidados odontológicos

- Aprendizagem de cuidados com a higiene bucal

- Eliminação de focos de dor

- Melhoria geral da saúde

- Aumento da produtividade e da motivação

GUIMARÃES e ROCHA ${ }^{29}$ (1979);FERREIRA ${ }^{23}$ (1997); MIDORIKAWA ${ }^{40}$ (2000); PINTO ${ }^{56}$ (2002) 
Benefícios para a empresa:

- Diminuição do absenteísmo

- Maior produtividade industrial

- Diminuição dos problemas médicos

- Diminuição de acidentes de trabalho

- Dedução do imposto de renda

- Melhoria da imagem da empresa no mercado

GUIMARÃES e ROCHA ${ }^{29}$ (1979);MIDORIKAWA ${ }^{40}$ (2000);

PIMENTEL $^{57}$ (1976); PINTO ${ }^{56}$ (2002)

Benefícios para o Brasil:

- Diminuição da demanda e da procura pelos serviços odontológicos dos órgãos públicos

- Atendimento a outras categorias

- Diminuição de acidentes de trabalho

- Aumento da produção e oferta do produto industrializado nacional GUIMARÃES e ROCHA ${ }^{29}$ (1979); MIDORIKAWA ${ }^{40}$ (2000); PIMENTEL $^{54}$ (1976); PIZZATO ${ }^{58}$ (2002)

Diante de tantos benefícios é clara a importância da prestação de serviços odontológicos aos trabalhadores, devendo esta preferivelmente ser disponibilizada no próprio local de trabalho, interferirindo o mínimo possível na produção (MEDEIROS e BIJELLA ${ }^{38}, 1971$; PINTO ${ }^{56}$, 2000).

DUNNING ${ }^{18}$ et al.(1941), realizaram estudo em indústrias americanas para verificar a existência e a características dos serviços 
odontológicos. Das 869 indústrias cerca de 18,81\% disponibilizavam assistência odontológica a seus empregados, sendo que os tratamentos mais simples como exame, profilaxia e uma pequena gama de procedimentos era custeado pela empresa, e em alguns casos parte do custo era repassado para os funcionários. O autor cita que somente empresas com mais de 500 funcionários apresentam serviço médico especializado e mantém algum tipo de serviço odontológico.

O exame odontológico é tão importante que desde 1964, BRITO $^{10}$, tentou instituí-lo como lei, por meio de um projeto que fixava o exame odontológico obrigatório para o ingresso tanto em escolas como em empresas. O autor justifica a importância desta ação, como sendo a boca fonte da maioria das doenças, essa medida preventiva visava manter a saúde humana.

Em 1970, MEDEIROS e BIJELA ${ }^{37}$, mostraram a importância da Odontologia dentro de uma indústria, apresentando bases para a organização de programas odontológicos para trabalhadores. Os autores estabelecem uma relação mínima de 500 funcionários para a instalação de um serviço odontológico, e um máximo de 1.500 funcionários por CD.

O atendimento odontológico dentro da empresa ofereceria ao empregador, funcionários em perfeitas condições de saúde bucal, melhorando indiretamente a produtividade, reduzindo o absenteísmo e riscos com acidentes de trabalho (GUIMARÃES e ROCHA ${ }^{29,30,31}, 1979$ ). No mesmo ano esses autores apresentam o conceito da Odontologia do Trabalho como 
sendo " a parte da odontologia que trata de promover, preservar e reparar a saúde do trabalhador, conseqüente dos agravos, afecções ou doenças advindas do exercício profissional e que se manifeste na boca". Defendem a realização de exame odontológico admissional, censo odontológico, exames periódicos, e campanhas educativas para os trabalhadores.

$\mathrm{Na}$ tentativa de demonstrar a necessidade da manutenção dos serviços odontológicos em uma empresa, GOMES e MAGALHÃES ${ }^{28}$, em 1980, realizaram um estudo baseado em dados obtidos através de um levantamento epidemiológico de funcionários da Administração Geral da Rede de Ferroviária Federal S.A. Destacaram a importância da assistência odontológica, permitindo detectar enfermidades em seu estágio inicial, desta forma adotando tratamento adequado e rápido, evitando maiores danos ao funcionário e à empresa.

MOTTA e ALBUQUERQUE ${ }^{45}$ (1983), organizaram e implantaram serviço odontológico em uma indústria mecânica, buscando conciliar os atendimentos sem prejudicar o andamento dos demais serviços na empresa. Os autores ressaltam a importância do exame odontológico admissional, censo odontológico, avaliação periódica e campanhas educativas. Após um ano de avaliação os mesmos autores (MOTTA e ALBUQUERQUE $\left.{ }^{45}, 1983\right)$ afirmaram que o plano odontológico atingiu seus objetivos controlando as doenças bucais e evitando a ausência do funcionário do seu local de trabalho. 
SILVA e SOUTO ${ }^{60,61,62}$, em 1985, publicaram três estudos sobre modelo de serviço assistencial em odontologia ocupacional, defendendo a idéia de que programas odontológicos nas empresas visam facilitar o acesso e preservar a saúde bucal dos trabalhadores. Ressaltam a importância de exames odontológicos admissionais, periódicos, censo odontológico e participação em campanhas educativas e de prevenção. Ressaltam que a assistência odontológica ao trabalhador deve ser implantada pela empresa, visto que a saúde é importante na melhora da produtividade.

O benefício odontológico pode ser oferecido aos trabalhadores sob diferentes formas (ZATS, LANDAY, LEDELL ${ }^{75}, 1989$ ). A empresa pode oferecer um plano de saúde que enquadre os serviços básicos e especializados (NO AUTHORS LISTED ${ }^{48}, 1980$ ), porém a maioria delas apresentam planos que se restringem às atividades restauradoras-curativas $\left(\right.$ PIZZATO $^{58}, 2002$; STEZEL $\left.{ }^{68}, 2000\right)$, excluindo procedimentos estéticos e protéticos.

O ambiente de trabalho pode contribuir para o aumento dos índices de doenças bucais, por isso atividades de promoção de saúde, devem estar integradas às rotinas de atividades dos trabalhadores (MASSALIN $\left.{ }^{34}, 1994\right)$. Após a instalação de um serviço odontológico dentro de uma empresa, há diminuição dos níveis de doenças bucais (MOTA e TOLEDO $^{46}$, 1983). Porém para existir sucesso, é fundamental a participação ativa dos trabalhadores, uso de pessoal para auxiliar o $C D$, além da realização de métodos preventivos e educativos $\left(\mathrm{SCHOU}^{66}, 1989\right)$. 
SO e SCHWARZ ${ }^{66}$ (1995), realizaram estudo com o intuito de verificar a existência de serviços odontológicos em empresas de Hong Kong. Foram pesquisadas somente empresas com mais de 100 funcionários, e foi observado que apenas $16 \%$ ofereciam este benefício. E o tipo poderia ser dividido em: benefício dinheiro e benefício serviço, sendo os itens cobertos pelos planos na maior parte serviços simples. No ano seguinte, os mesmos autores (SO e SCHWARZ ${ }^{67}$, 1996), analisaram o comportamento de trabalhadores em relação aos serviços odontológicos. Verificaram que $40 \%$ dos trabalhadores não tinham ciência do benefício oferecido. Concluíram portanto que a simples oferta de serviços de assistência não traz benefícios em termos de saúde para o trabalhador, medidas adicionais são necessárias.

ARAÚJO e JÚNIOR ${ }^{3}$, em 1999, destacaram a saúde do trabalhador como um campo de atuação profissional para o cirurgiãodentista. Que deve abordar de forma objetiva a epidemiologia e patologia das doenças ocupacionais, prevenindo os efeitos nocivos das condições de trabalho e suas influências sobre a saúde bucal preservando-a como fator significante da saúde geral.

A implantação de serviços odontológicos para os trabalhadores é extremamente importante porque, de acordo com PINTO ${ }^{56}$ (2000), esta parcela da população apresenta alta prevalência de problemas bucais, higiene bucal deficiente, além de dificuldades de acesso ao tratamento odontológico devido ao tempo escasso pela jornada de trabalho e aos baixos 
salários que os impedem de procurar serviços particulares de atenção à Saúde Bucal.

Com o objetivo de mostrar a importância da presença do cirurgião-dentista na equipe de Saúde do Trabalhador, MIDORIKAWA ${ }^{40}$ em 2000, realizou estudo sobre a Odontologia em Saúde do Trabalhador, para tanto selecionou empresas no CIESP que possuíam mais de 1000 empregados, acusando um número de 249 empresas. Destas foram selecionadas 75 , que receberam carta com o questionário da pesquisa, apenas oito responderam $(10,66 \%)$, sendo que sete apresentavam serviço odontológico na empresa. Todas as empresas pesquisadas consideram a saúde bucal importante para o bom desempenho dos funcionários. O autor define ainda as funções do cirurgião-dentista especialista em Odontologia do Trabalho:

- Prevenção, diagnóstico e tratamento das manifestações bucais de doenças profissionais

- Avaliações técnicas de tratamentos odontológicos

- Perícia no campo trabalhista e civil

- Colaboração com a equipe de segurança e saúde no trabalho.

Oficialmente a especialidade Odontologia do Trabalho é muito recente (BRASIL $\left.{ }^{9}, 2002\right)$, porém há muito tempo se discute a saúde bucal dos trabalhadores. Desde 1943 PETTY $^{55}$ publicou um artigo que citava a odontologia industrial como uma especialidade preocupada com a saúde dental do trabalhador. Em 1966 MEDEIROS $^{36}$, define a Odontologia do 
Trabalho como setor da odontologia com a finalidade de melhoria da saúde bucal, efeitos e influência sobre a produtividade e o diagnóstico precoce de manifestações bucais de doenças profissionais.

Comprovando a eficácia de programas preventivos desenvolvidos nos próprios locais de trabalho, FISHWICK, ASLEY, WILSON $^{24}$ (1998), realizaram um estudo em 98 trabalhadores em boas condições de saúde geral, avaliando as condições periodontais antes e após o desenvolvimento de um programa preventivo. Os resultados apontaram significativa redução do sangramento gengival e bolsas periodontais, confirmando a eficácia clínica de campanhas de conscientização desenvolvidas no ambiente de trabalho.

A evolução no campo da saúde do trabalhador tem sido lenta e com poucos avanços de acordo com OLIVEIRA e VASCONCELLOS ${ }^{51}$ (2000). Os autores discutem as políticas públicas brasileiras de saúde do trabalhador, e inserem este como elemento atuante que precisa se envolver em todas as etapas do processo de construção de sua própria saúde.

IDE ${ }^{33}$ et al., em 2001, avaliaram o impacto da promoção de saúde bucal no local de trabalho em termos de custos e freqüência de visitas ao dentista. Foi realizado num grupo um programa de orientação sobre higiene e prevenção de doenças bucais, comparando com o grupo controle verificou-se que o programa de promoção de saúde bucal no ambiente de trabalho contribuiu para reduzir custos associados aos tratamentos 
odontológicos e que o ambiente de trabalho pode ser a chave para a implantação de sistemas que visem a melhoria da saúde.

Da mesma forma, MORISHITA et al. ${ }^{44}$, em 2003, avaliou a efetividade de um programa de promoção de saúde bucal no ambiente de trabalho, obteve conclusões semelhantes ao trabalho anterior, sendo o programa efetivo para manutenção de bons níveis de saúde bucal nos trabalhadores, salientando a educação para motivar os funcionários a realizarem exames periódicos.

Foi realizado um estudo para avaliar a existência e o tipo do benefício odontológico oferecido por empresas de médio e grande porte do município de Bauru. A amostra incluiu 30 empresas e destas 19 (63,3\%) ofereciam assistência odontológica a seus funcionários, sendo o tipo predominante convênio com CD em consultório particular. A saúde bucal foi considerada importante para o bom desempenho do funcionário por $83,3 \%$ das empresas, que também afirmaram que o acesso ao tratamento odontológico poderia ser facilitado por elas (CIRILO et al. $\left.{ }^{12}, 2002\right)$.

No mesmo ano 2002, PIZZATO ${ }^{58}$ buscou identificar as práticas de saúde voltadas para os trabalhadores, mais especificamente a existência de programas de atenção em saúde bucal. Para tanto coletou informações em 47 empresas, por meio de questionário, e observou que 16 indústrias (34,04\%) oferecem serviço odontológico, apresentando correlação positiva com o tamanho da empresa. A prática verificada nestes industriais pesquisados é predominantemente curativo-restauradora, com pouca ênfase 
em atividades preventivas. Os principais motivos citados para 0 funcionamento de um programa odontológico na empresa foram: aumentar a satisfação e colaboração dos trabalhadores, diminuir o absenteísmo e promover a saúde bucal nesta ordem.

"O benefício odontológico fica, conforme a legislação trabalhista, a cargo da empresa" FERREIRA ${ }^{22}$ (1995). Embora a legislação ainda não torne a especialidade Odontologia do Trabalho obrigatória (MINGUEZ $\left.{ }^{42}, 2004\right)$, muitas empresas e conseqüentemente a nação podem apresentar prejuízos altos advindos da impossibilidade de trabalhadores exercerem suas funções em decorrência de males que afetam a cavidade bucal. Desta forma é fundamental que os programas de saúde ocupacional incluam a odontologia (ASSIS $\left.{ }^{4}, 2004\right)$, pois no Brasil a maior parte da população ainda não tem acesso à odontologia, que se apresenta na realidade com caráter privativo, individualista e de altos custos ${ }^{27}$. 
3 PROPOSIÇÃO 


\section{PROPOSIÇÃO}

Este estudo tem como objetivos verificar:

3.1 - A existência e o tipo de assistência odontológica oferecida por empresas de grande porte nos municípios que compõem a DIR X, no Estado de São Paulo.

3.2 - A condição de saúde bucal funcionários com idade de 34 a 44 anos, comparando com as metas da OMS para os anos de 2000 e 2010.

3.3 - O uso e satisfação dos trabalhadores frente ao benefício odontológico oferecido por uma das empresas pesquisadas. 
4 MATERIAL E MÉTODOS 


\section{MATERIAL E MÉTODOS}

\subsection{População - alvo}

Este estudo foi realizado em todas as empresas de grande porte presentes nos municípios que compõe a Diretoria Regional de Saúde DIR X e que apresentam cadastro no CIESP (Centro de Indústria do Estado de São Paulo).

A Diretoria Regional de Saúde é uma divisão administrativa dentro da área da saúde. No Estado de São Paulo existem 24 regionais administrativas, sendo a primeira situada na capital e as demais espalhadas por todo e estado (Tabela 1).

TABELA 1 - Descrição das DIRs de acordo com a cidade, 2004.

\begin{tabular}{|c|c|}
\hline DIR & Cidade \\
\hline DIR I & Capital \\
\hline DIR II & Santo André \\
\hline DIR III & Mogi das Cruzes \\
\hline DIR IV & Franco da Rocha \\
\hline DIR V & Osasco \\
\hline DIR VI & Araçatuba \\
\hline DIR VII & Araraquara \\
\hline DIR VIII & Assis \\
\hline DIR IX & Barretos \\
\hline DIR $X$ & Bauru \\
\hline DIR XI & Botucatu \\
\hline DIR XII & Campinas \\
\hline DIR XIII & Franca \\
\hline DIR XIV & Marília \\
\hline DIR XV & Piracicaba \\
\hline DIR XVI & Presidente Prudente \\
\hline DIR XVII & Registro \\
\hline DIR XVIII & Ribeirão Preto \\
\hline DIR XIX & Santos \\
\hline DIR XX & São João da Boa Vista \\
\hline DIR XXI & São José dos Campos \\
\hline DIR XXII & São José do Rio Preto \\
\hline DIR XXIII & Sorocaba \\
\hline DIR XXIV & Taubaté \\
\hline
\end{tabular}


A escolha da DIR X se baseou na área de interesse com sede na cidade de Bauru, que apresenta 38 municípios sob sua supervisão (Figura 1).

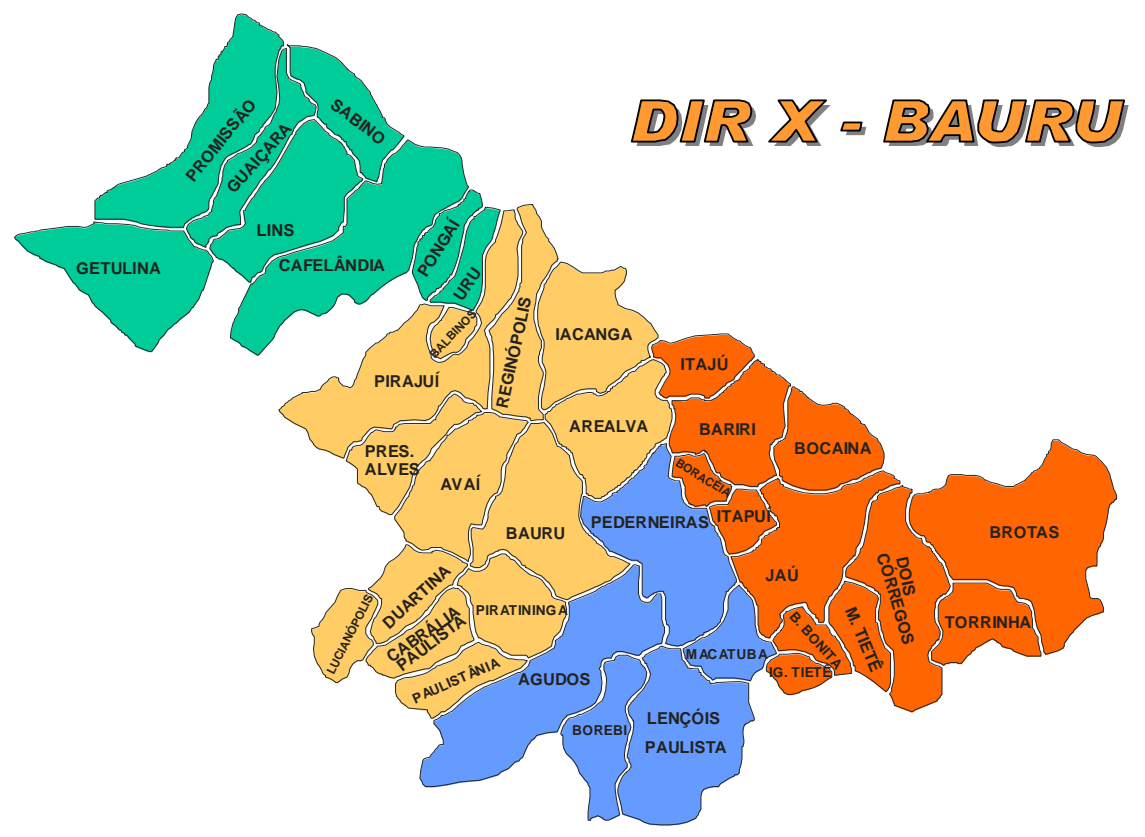

FIGURA 1 - Mapa com os 38 municípios pertencentes à DIR X, 2004.

Porém nem todos os municípios da DIR $X$ apresentam empresas de grande porte, esta classificação foi definida de acordo com critério adotado pelo CIESP, que estrutura o porte da empresa de acordo com o número de funcionários (Tabela 2). 
TABELA 2 - Porte da empresa de acordo com critério do CIESP, 2004.

\begin{tabular}{c|c}
\hline Porte da empresa & $N^{o}$ de funcionários \\
\hline Micro & $0-9$ \\
\hline Pequena & $10-99$ \\
\hline Média & $100-499$ \\
\hline Grande & Acima de 500
\end{tabular}

Portanto dentro da área de interesse somente alguns municípios apresentam empresas de grande porte (Tabela 3).

TABELA 3 - Municípios da DIR X com respectivo número de empresas de grande porte, 2004.

\begin{tabular}{c|c}
\hline Cidade & $\begin{array}{c}\mathbf{N}^{\mathbf{o}} \text { de empresas de } \\
\text { grande porte }\end{array}$ \\
\hline Barra Bonita & 01 \\
\hline Bauru & 06 \\
\hline Jaú & 02 \\
\hline Lencóis & 05 \\
\hline Lins & 01 \\
\hline & 01 \\
\hline Presidente Alves & 01 \\
\hline Promissão & 02 \\
\hline & $\mathbf{1 9}$ \\
\hline
\end{tabular}

As empresas pesquisadas se diferenciam segundo o ramo de atividade, que é classificado de acordo com o Código Nacional de Atividade Econômica (CNAE) da Secretaria da Receita Federal. Portanto a área de atividade das 19 empresas foram diferentes, sendo que a maioria $(n=6 /$ 
31,58\%) representam usinas de álcool e açúcar, seguido de empresas ( $n=4$ / 21,05\%) que atuam como frigoríficos, 2 (10,52\%) indústrias de acessórios de vestuários, 1 (5,26\%) indústria alimentícia, 1 (5,26\%) fábrica de baterias, $1(5,26 \%)$ que realiza serviços de impressão, 1 (5,26\%) fábrica de celulose, $1(5,26 \%)$ indústria têxtil, $1(5,26 \%)$ indústria de refino de petróleo e $1(5,26)$ que atua no setor de edificações.

\subsection{Delineamento do estudo}

Este estudo transversal foi realizado em uma fase inicial exploratória através de pesquisa documental bibliográfica e numa segunda fase de pesquisa de campo, onde foi realizada entrevista nas empresas da amostra citada anteriormente.

\subsection{Etapas do trabalho de campo}

\subsubsection{Implicações éticas}

Este estudo foi submetido, juntamente com o protocolo de pesquisa, ao Comitê de Ética em Pesquisa, da Faculdade de Odontologia de Bauru - Universidade de São Paulo, segundo a resolução 196/96, do Conselho Nacional de Saúde, tendo sido aprovado em 31 de março de 2004 (Anexo 3). 
Sendo assim, inicialmente os funcionários da empresa recebiam uma Carta de Informação (Anexo 4 e 5), explicitando: o objetivo do projeto e sua execução, após sua leitura e explicação verbal, ciente a que seria submetido o participante da pesquisa firmava seu Consentimento Livre e Esclarecido, assentindo em participar da pesquisa proposta mediante a assinatura.

\subsubsection{Estudo Piloto}

Foi conduzido um estudo piloto, onde duas empresas de médio porte participaram, e os exames foram feitos numa amostra de 25 funcionários por empresa.

Com a execução do piloto pode-se observar que a palestra sobre cuidados com a saúde bucal em adultos, idealizada inicialmente, não seria possível devido o afastamento do funcionário de seu posto de serviço.

\subsubsection{Coleta de dados}

As 19 empresas selecionadas foram contatadas inicialmente por telefone, onde foi explicada a natureza e objetivos do estudo, após alguns esclarecimentos eram convidadas a participar da pesquisa, sendo portanto de caráter voluntário sua participação.

Quando aceito o convite, era agendada uma visita à empresa, quando seria realizada a entrevista baseada no questionário (Anexo 6) no 
setor administrativo, respondido pela assistente social, psicóloga ou outro profissional responsável pela parte dos benefícios oferecidos pela empresa.

\subsubsection{Exame bucal}

Em todas as empresas onde foi realizada a pesquisa no setor administrativo, tentou-se também permissão para realizar pesquisa com uma amostra dos funcionários. Esta segunda etapa não foi possível na grande maioria das empresas, pois a permissão foi negada. Alguns fatores colaboraram para o insucesso desta fase, como a proximidade do fim de ano onde a produção de modo geral aumenta sobremaneira, associada ao receio dos administradores em prejudicar o andamento da produção.

Porém uma das empresas pesquisadas autorizou a execução desta segunda etapa do estudo, feita em uma amostra por conveniência de 100 funcionários que responderam um questionário (Anexo 7) e passou por exame bucal, mais especificamente das condições dentárias, baseado na presença de dentes e próteses.

O exame foi realizado por uma única examinadora, a autora, sob luz natural e auxílio de espátula de madeira para afastar tecidos moles, baseado na metodologia da OMS, isto é códigos e critérios de acordo com formulário simplificado (Anexo 8) foi possível realizar a coleta de dados de modo sistemático, possibilitando futuras comparações. 
Foi escolhido um local da empresa onde os trabalhadores necessariamente transitassem, a entrada do refeitório, que apresentava em determinados horários, fluxo bastante intenso. A maioria dos funcionários era abordada, enquanto outros se aproximavam na busca de informações. Foram necessários cinco dias não consecutivos para conseguir a amostra determinada de 100 exames.

A inclusão dos funcionários que passaram por exame bucal se baseou na idade, portanto participaram do estudo aqueles que apresentavam 35 a 44 anos, grupo etário recomendado pela OMS para monitorização das condições de saúde nos adultos.

De acordo com o formulário simplificado, foram coletados dados referentes a condição e necessidade protética. Os campos referentes a esses dados são idênticos aos encontrados na Ficha de Avaliação da Saúde Bucal da Organização Mundial de Saúde OMS ${ }^{52}$ (1999). Já a presença e ausência dos dentes foram determinadas de acordo com critérios para verificar se as condições funcionais e estéticas do dente estavam presentes, de modo que, uma raiz residual era considerada dente ausente e um dente cuja raiz estava presente e foi restabelecido proteticamente, era considerado dente presente.

A necessidade de prótese foi considerada se o indivíduo não fazia uso ou se a atual prótese deveria ser substituída. 
Os examinados se beneficiaram recebendo escova dentária (Anexo 9), orientações sobre Cuidados com a Saúde Bucal, através de um folheto (Anexo 10), além de orientações sobre os atendimentos na Faculdade de Odontologia (FOB-USP). Na tentativa de facilitar o acesso ao tratamento dos participantes da pesquisa uma lista contendo os nomes de todos os examinados foi deixada no setor da clínica de triagem da FOB.

Os resultados foram repassados às empresas participantes juntamente com a justificativa favorável da presença do cirurgião-dentista dentro da equipe de trabalho da saúde do trabalhador. Certamente preservando a identidade das empresas, assim como dos funcionários participantes.

4.3.5 Análise dos dados

Os dados coletados foram tabelados em planilha do Excel (Microsoft Co., USA) e os cálculos foram efetuados utilizando o programa Statistica for Windows versão 5.1 (Stat Soft Inc., USA).

Os resultados foram apresentados por meio de tabelas e gráficos com freqüências absoluta e relativa. 
5 RESULTADOS 


\section{RESULTADOS}

\subsection{Assistência odontológica nas empresas}

Das 19 empresas catalogadas pelo CIESP, o total de 15 (78,95\%) consentiram em participar desta pesquisa. Perdas da amostra ocorreram por motivos como recusa em participar ( $n=2 / 10,53 \%)$ e burocracias internas $(n=2 / 10,53 \%)$.

A assistência médica estava presente em todas as empresas, enquanto que o benefício odontológico era oferecido por 12 empresas (85,71\%), a Tabela 4 nos mostra o tipo de assistência desenvolvida.

Tabela 4 - Distribuição da amostra segundo o tipo de assistência odontológica desenvolvida em empresas de grande porte da DIR X , 2004

\section{TIPO}

\begin{tabular}{cc}
\multicolumn{2}{c}{ EMPRESA } \\
\hline $\mathrm{N}$ & $\%$
\end{tabular}

1. Convênio com $\mathrm{CD}$ em consultório particular

4

33,33

2. Convênio com Sistema de Saúde Odontológico

$0 \quad 0,00$

3. Consultório próprio CD contratado 3

25,00

4. Consultório próprio com CD prestador de serviço

18,33

5. Reembolso parcial do valor do tratamento

$0 \quad 0,00$

6. Associação 1 e 5

4

33,33 
A assistência odontológica predominante foi convênio com CD em consultório particular e uma associação entre oferecimento de convênio em consultório particular fora da empresa e reembolso parcial do valor do tratamento, neste caso o valor reembolsado era $50 \%$ do total do tratamento.

Com relação ao número de dentistas que atendem os funcionários, 2 empresas (16,67\%) não souberam responder, 5 delas $(41,67 \%)$ contam com apenas um profissional, e outras $5(41,67 \%)$ têm convênio com clínicas envolvendo mais de cinco cirurgiões-dentistas. Em todas as empresas que oferecem assistência existe um esforço para abranger todas as especialidades odontológicas, no entanto em 6 empresas (50\%) os procedimentos se limitam a clínica geral.

Nenhuma das empresas realiza exame odontológico admissional, e os funcionários também não são chamados para realização de exames periódicos.

A grande maioria das empresas $(n=11 / 91,66 \%)$ que oferece assistência odontológica, estendem o benefício não somente para o funcionário mas também à família deste.

Palestra anual para os funcionários envolvendo Saúde Bucal foi a atividade preventiva citada por 6 empresas (50\%). 
Com relação ao custo que o funcionário teria ao usar o benefício odontológico, em empresas que assumem o reembolso, o valor pago pelo funcionário é de $50 \%$ do total do tratamento, em outras modalidades como consultório dentro da empresa e CD contratado, o custo seria só relacionado à tratamentos protéticos, e em convênios com CD em consultório particular o trabalhador deve pagar um valor com desconto para o tratamento a ser realizado, de acordo com o consultório escolhido.

Não existe nas empresas um sistema de informação que ofereça dados sobre o uso que os funcionários façam do benefício odontológico.

Em todas as empresas o sistema de procura pelo benefício odontológico é livre-demanda, associado a agendamento daqueles que já se encontram em tratamento.

Somente 2 empresas responderam com certeza há quanto tempo existe o benefício odontológico: 10 anos em uma e 1 mês na outra, as demais não sabiam afirmar com segurança, porém certamente é superior a 2 anos. 
5.2 Saúde bucal do trabalhador

Uma das empresas participantes da pesquisa permitiu exames bucais em seus funcionários. Portanto foram selecionados através de uma amostra por conveniência 100 funcionários da linha de produção, que apresentavam idade entre 35 e 44 anos, o que possibilitaria futuras comparações com as metas da Organização Mundial.

O critério de inclusão dos funcionários que participaram da pesquisa, foi pertencerem à linha de produção (FERRAZ, BELINI, 1983), setor da empresa que conta com o maior número de trabalhadores, excluindo portanto, funcionários dos setores administrativos. Mesmo procurando balancear a amostra de acordo com o gênero, não foi possível visto que de acordo com o tipo de serviço e força necessária para realizá-lo uma porcentagem maior de homens trabalhavam na empresa em questão (Gráfico 1).

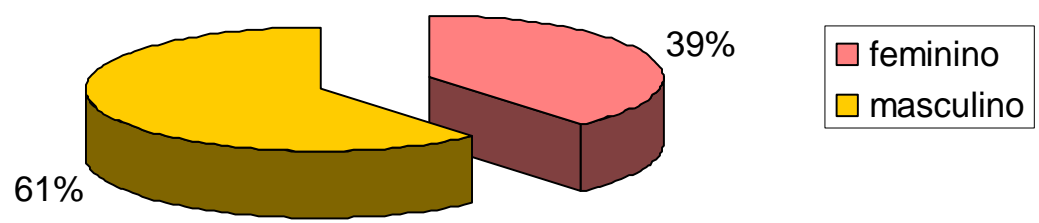

FIGURA 2 - Descrição da amostra de funcionários examinados acordo com o gênero, 2004 
Com relação ao número de dentes encontrados, podemos visualizar na Tabela 5.

TABELA 5 - Número médio de dentes, desvio padrão e porcentagem de dentes encontrados nos trabalhadores, de acordo com 0 gênero, 2004

\begin{tabular}{ccccc}
\hline GÊNERO & $\mathrm{N}$ & $\begin{array}{c}\text { Média } \mathrm{n}^{\mathrm{o}} \\
\text { de dentes }\end{array}$ & $\mathrm{dp}$ & $\begin{array}{c}\text { \% de dentes em } \\
\text { relação ao } \\
\text { número total } \\
\text { esperado }\end{array}$ \\
\hline $\mathrm{M}$ & 61 & 23,91 & 7,06 & 74,72 \\
$\mathrm{~F}$ & 39 & 19,43 & 9,65 & 60,71 \\
\hline TOTAL & 100 & 22,17 & 8,41 & 69,28 \\
\hline
\end{tabular}

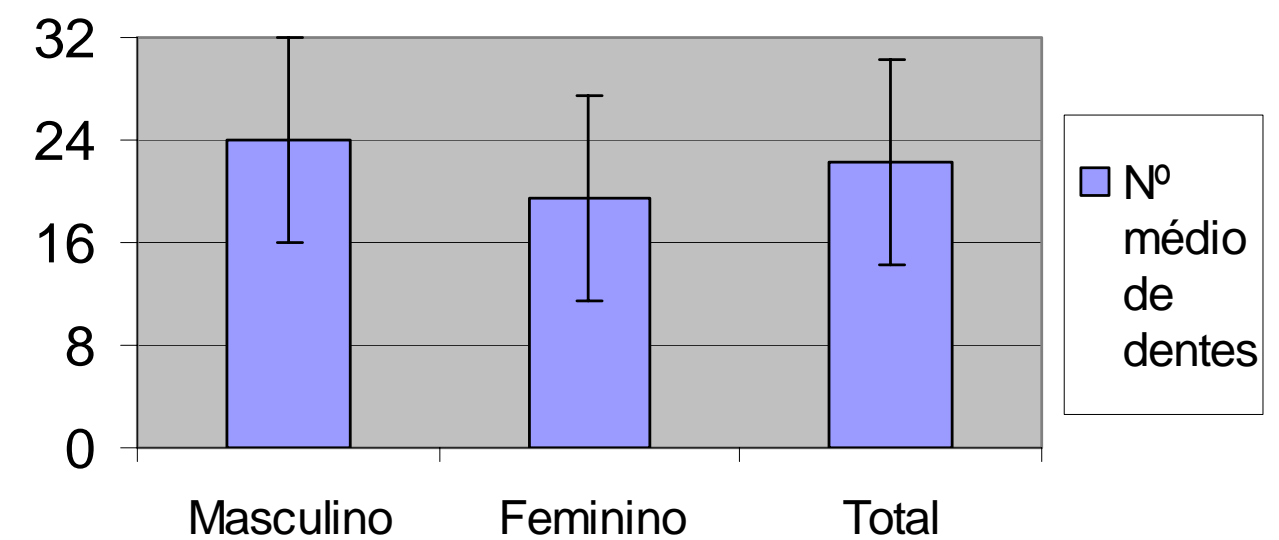

FIGURA 3 - Número médio de dentes encontrados em trabalhadores, de acordo com o gênero e com desvio padrão, Bauru, 2004

Dos trabalhadores com idade entre 35 a 44 anos, $70 \%$ apresentam 20 ou mais dentes na cavidade bucal. 
$\mathrm{O}$ dente que se apresentou mais ausente nos homens foi 0 primeiro molar inferior em ambos os lados, enquanto que nas mulheres foram os terceiros molares superiores. $O$ mais presente na maioria masculina foram os caninos inferiores e nas mulheres os incisivos inferiores.

Os resultados referentes à condição e necessidade protética demonstram que a maioria dos trabalhadores não utiliza prótese tanto na arcada superior (63\%) como na inferior (88\%) (Tabelas 6 e 7).

TABELA 6 - Condição protética da arcada superior de trabalhadores de acordo com o gênero, 2004

\begin{tabular}{c|c|c|c|c|c|c|c|c}
\hline \multirow{2}{*}{ Gênero } & \multicolumn{9}{c}{ Condição Protética Superior } & \multicolumn{2}{c}{ Total } \\
\cline { 2 - 8 } & \multicolumn{2}{|c|}{ Sem Prótese } & \multicolumn{2}{c}{ PPR } & \multicolumn{2}{c}{ PT } & \multicolumn{2}{c}{} \\
\hline & $\mathrm{N}$ & $\%$ & $\mathrm{~N}$ & $\%$ & $\mathrm{~N}$ & $\%$ & $\mathrm{~N}$ & $\%$ \\
Masculino & 43 & 70,49 & 12 & 19,67 & 6 & 9,84 & 61 & 100,00 \\
\hline Feminino & 20 & 51,28 & 6 & 15,38 & 13 & 33,33 & 39 & 100,00 \\
\hline \hline Total & 63 & $63,00 \%$ & 18 & $18,00 \%$ & 19 & $19,00 \%$ & 100 & 100,00 \\
\hline \hline
\end{tabular}

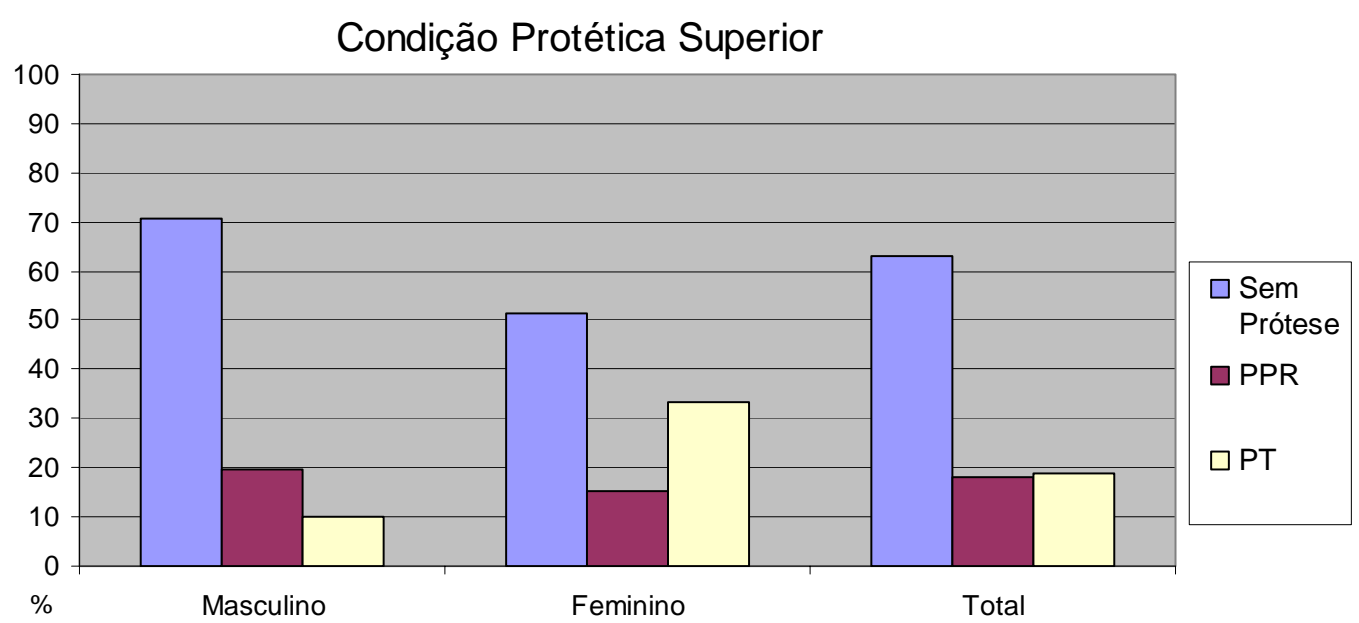

FIGURA 4 - Condição protética da arcada superior de trabalhadores de acordo com o gênero, 2004 
Nota-se que as mulheres fazem mais uso de PT superior comparado aos homens.

TABELA 7 - Condição protética da arcada inferior de trabalhadores de acordo com o gênero, 2004

\begin{tabular}{|c|c|c|c|c|c|c|c|c|c|c|}
\hline \multirow{2}{*}{ Gênero } & \multicolumn{8}{|c|}{ Condição Protética Inferior } & \multirow{2}{*}{\multicolumn{2}{|c|}{ Total }} \\
\hline & \multicolumn{2}{|c|}{ Sem Prótese } & \multicolumn{2}{|c|}{ PPF } & \multicolumn{2}{|c|}{ PPR } & \multicolumn{2}{|c|}{ PT } & & \\
\hline Masculino & $\begin{array}{l}\mathrm{N} \\
55\end{array}$ & $\begin{array}{c}\% \\
90,16\end{array}$ & $\begin{array}{l}\mathrm{N} \\
0\end{array}$ & $\begin{array}{c}\% \\
0,00\end{array}$ & $\begin{array}{l}N \\
6\end{array}$ & $\begin{array}{c}\% \\
9,84 \\
\end{array}$ & $\begin{array}{l}\mathrm{N} \\
0\end{array}$ & $\begin{array}{c}\% \\
0,00\end{array}$ & $\begin{array}{l}\mathrm{N} \\
61\end{array}$ & $\begin{array}{c}\% \\
100,00\end{array}$ \\
\hline Feminino & 33 & 84,62 & 1 & 2,56 & 3 & 7,69 & 2 & 5,13 & 39 & 100,00 \\
\hline Total & 88 & 88,00 & 1 & 1,00 & 9 & 9,00 & 2 & 2,00 & 100 & 100,00 \\
\hline
\end{tabular}

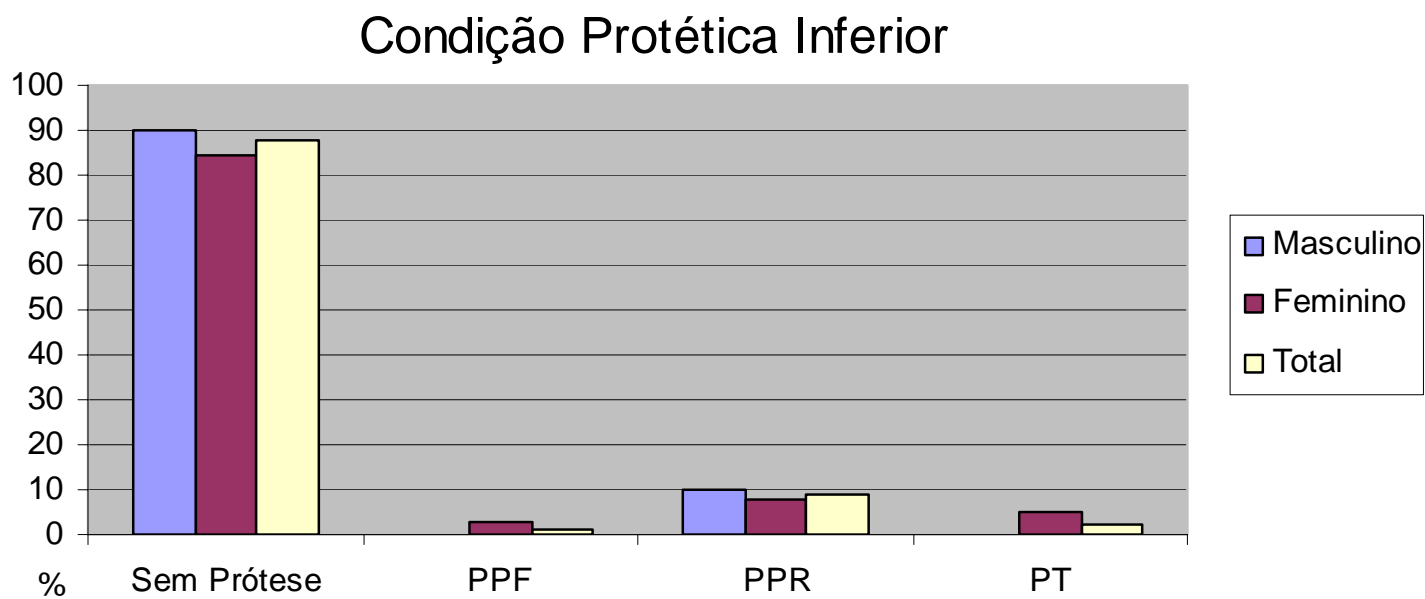

FIGURA 5 - Condição protética da arcada inferior de trabalhadores de acordo com o gênero, 2004 
TABELA 8 - Necessidade protética da arcada superior de trabalhadores de acordo com o gênero, 2004

\begin{tabular}{|c|c|c|c|c|c|c|c|c|c|c|}
\hline \multirow{3}{*}{ Gênero } & \multicolumn{8}{|c|}{ Necessidade Protética Superior } & \multirow{2}{*}{\multicolumn{2}{|c|}{ Total }} \\
\hline & \multicolumn{2}{|c|}{$\begin{array}{c}\text { Não } \\
\text { Necessita }\end{array}$} & \multicolumn{2}{|c|}{$\begin{array}{l}\text { Prótese } \\
\text { Unitária }\end{array}$} & \multicolumn{2}{|c|}{$\begin{array}{l}\text { Prótese com } \\
\text { múltiplos } \\
\text { elementos }\end{array}$} & \multicolumn{2}{|c|}{$\begin{array}{l}\text { Associação } \\
\text { de Próteses }\end{array}$} & & \\
\hline & $\mathrm{N}$ & $\%$ & $\mathrm{~N}$ & $\%$ & $\mathrm{~N}$ & $\%$ & $\mathrm{~N}$ & $\%$ & $\mathrm{~N}$ & $\%$ \\
\hline Masculino & 37 & 60,66 & 10 & 16,39 & 14 & 22,95 & 0 & 0,00 & 61 & 100,00 \\
\hline Feminino & 26 & 66,67 & 3 & 7,69 & 9 & 23,08 & 1 & 2,56 & 39 & 100,00 \\
\hline Total & 63 & 63,00 & 13 & 13,00 & 23 & 23,00 & 1 & 1,00 & 100 & 100,00 \\
\hline
\end{tabular}

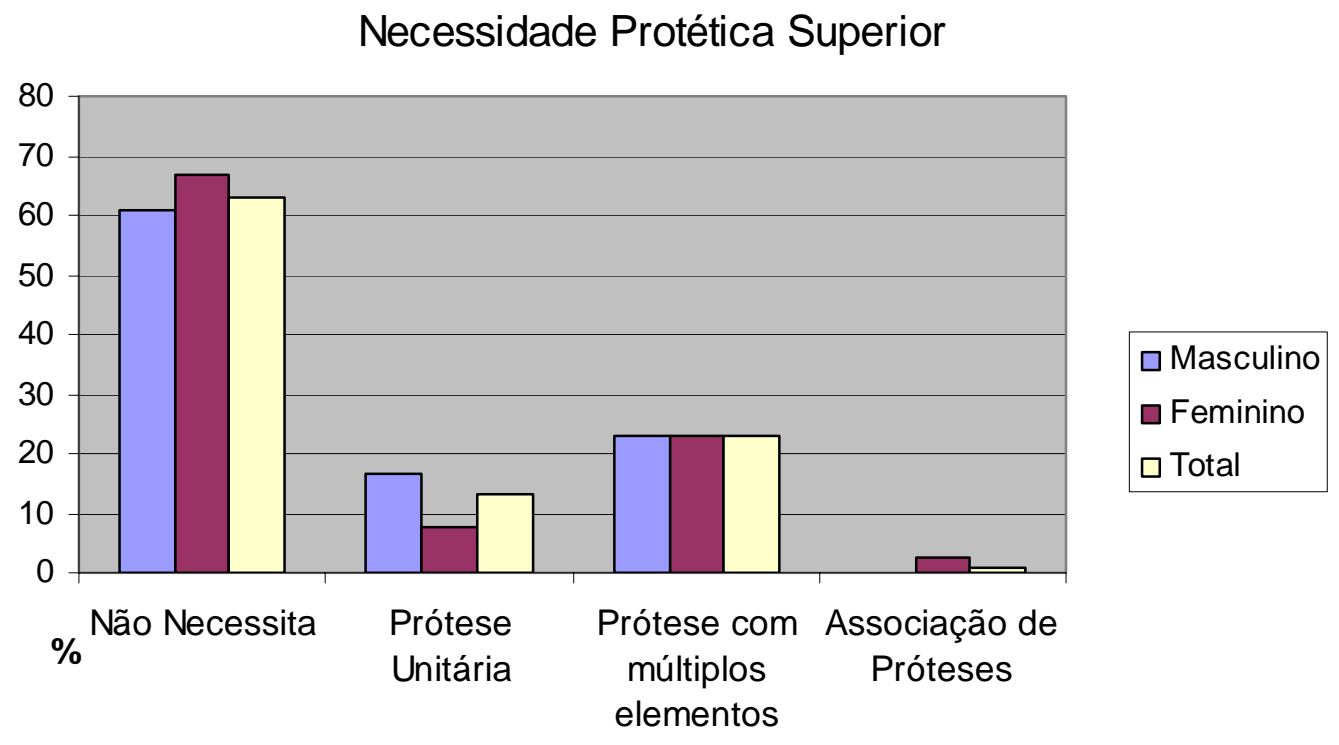

FIGURA 6 - Necessidade protética da arcada superior de trabalhadores de acordo com o gênero, 2004 
TABELA 9 - Necessidade protética da arcada inferior de trabalhadores de acordo com o gênero, 2004

\begin{tabular}{|c|c|c|c|c|c|c|c|c|c|c|}
\hline \multirow{3}{*}{ Gênero } & \multicolumn{8}{|c|}{ Necessidade Protética Inferior } & \multirow{2}{*}{\multicolumn{2}{|c|}{ Total }} \\
\hline & \multicolumn{2}{|c|}{$\begin{array}{c}\text { Não } \\
\text { Necessita }\end{array}$} & \multicolumn{2}{|c|}{$\begin{array}{l}\text { Prótese } \\
\text { Unitária }\end{array}$} & \multicolumn{2}{|c|}{$\begin{array}{c}\text { Prótese com } \\
\text { múltiplos } \\
\text { elementos }\end{array}$} & \multicolumn{2}{|c|}{$\begin{array}{l}\text { Associação } \\
\text { de Próteses }\end{array}$} & & \\
\hline & $\mathrm{N}$ & $\%$ & $\mathrm{~N}$ & $\%$ & $\mathrm{~N}$ & $\%$ & $\mathrm{~N}$ & $\%$ & $\mathrm{~N}$ & $\%$ \\
\hline Masculino & 12 & 19,67 & 16 & 26,23 & 31 & 50,82 & 2 & 3,28 & 61 & 100,00 \\
\hline Feminino & 13 & 33,33 & 3 & 7,69 & 21 & 53,85 & 2 & 5,13 & 39 & 100,00 \\
\hline Total & 25 & 25,00 & 19 & 19,00 & 52 & 52,00 & 4 & 4,00 & 100 & 100,00 \\
\hline
\end{tabular}

\section{Necessidade Protética Inferior}

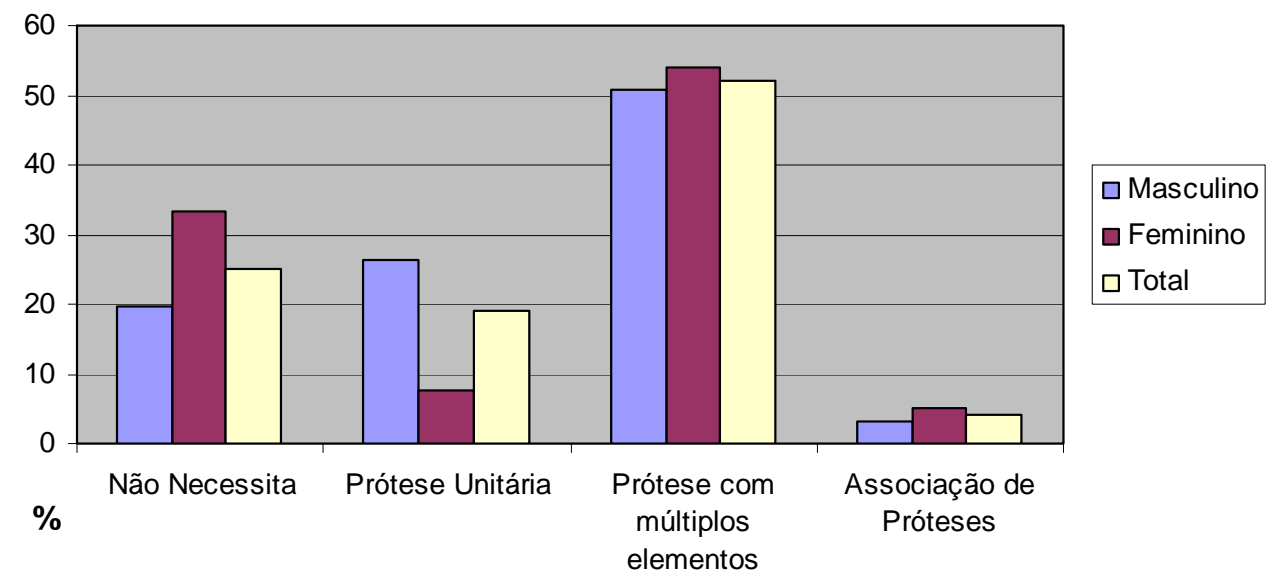

FIGURA 7 - Necessidade protética da arcada inferior de trabalhadores de acordo com o gênero, 2004

A prótese com múltiplos elementos, mais especificamente a prótese parcial removível, já que as perdas são bilaterais, é a maior necessidade da arcada inferior tanto em homens quanto em mulheres. 
$\mathrm{Na}$ empresa onde foi realizada a segunda etapa da pesquisa, a maioria dos funcionários (91\%) conhece os benefícios oferecidos. A assistência odontológica em questão é com consultório dentro da empresa e CD prestador de serviços, o funcionário portanto paga um valor reduzido quando comparado às clínicas particulares, sobre o tratamento a ser realizado.

Mesmo assim 68\% dos trabalhadores nunca utilizaram o convênio, sendo o principal motivo relatado o custo, seguido de "falta de tempo e não precisar". Dos que utilizam somente em $12 \%$ dos casos a família também faz uso do convênio.

Quando questionados sobre o que poderia melhorar na assistência odontológica prestada, $62 \%$ citou que os valores repassados para os funcionários poderiam ser menores, $8 \%$ reclamaram dos horários que são poucos, $24 \%$ não responderam e $6 \%$ melhorariam os serviços oferecidos, incluindo mais especialidades odontológicas como ortodontia.

Já foram trabalhar sentindo dor de dente $55 \%$ dos trabalhadores, porém $80 \%$ relataram nunca ter faltado ao serviço por motivos odontológicos. 
6 DISCUSSÃO 


\section{DISCUSSÃO}

\subsection{Da metodologia}

Normalmente, empresas de grande porte, ou seja, com mais de 500 funcionários, são as que possibilitam maiores benefícios a seus empregados. Dentre os quais, serviços odontológicos (DUNNING et al. ${ }^{18}$, 1941; WALDMAN ${ }^{73}$, 1995; PIZZATO $\left.{ }^{58}, 2002\right)$. Por isso a escolha desta categoria para o estudo, pois no Brasil esse benefício não é obrigatório, ficando a cargo da empresa decidir sua implantação ou não (MINGUEZ ${ }^{42}$, 2004).

Acredita-se que a metodologia utilizada nesta pesquisa, para a obtenção das respostas dos questionários, com comunicação prévia e deslocamento da entrevistadora até a empresa possa ter influenciado na grande participação no estudo (78,95\%). Este resultado destoa de estudos descritos na literatura onde as taxas de respostas apresentam-se baixas 10,66\% (MIDORIKAWA $\left.{ }^{40}, 2000\right)$ e $59 \%$ (DUNNING et al. ${ }^{18}, 1941$ ), sendo que o método utilizado envio de questionário via correspondência.

A permissão da empresa para a realização da pesquisa com seus funcionários ficou prejudicada devido à época em que os dados foram coletados. No último trimestre do ano, normalmente, a produção industrial aumenta consideravelmente, exigindo mais horas de trabalho e atenção dos 
trabalhadores. A coleta se deu nos meses de outubro a dezembro, prejudicando a aceitação em participar nesta etapa do estudo.

Com relação à realização de exames bucais em trabalhadores, a seleção dos funcionários por conveniência é uma alternativa em estudos realizados em empresas $\left(A B E E G^{1}, 1997\right)$, onde existe a preocupação em interferir o mínimo possível na rotina de produção. Além disso, os exames foram realizados por uma única examinadora, assim como em DINI'16 (1995), oferecendo dados mais confiáveis.

\subsection{Dos resultados}

\subsubsection{Assistência Odontológica nas empresas}

"Qualquer problema de origem bucal pode provocar desconforto físico, emocional, prejuízos consideráveis a saúde geral, além de diminuir a produtividade de um empregado dentro de sua função" (FERREIRA ${ }^{23}$, 1997). Portanto, é extremamente importante oferecer assistência odontológica a trabalhadores, com o objetivo de reduzir problemas bucais que interfiram na produtividade da empresa. 
A atenção à saúde bucal deveria fazer parte das preocupações com a saúde do trabalhador. Todas as empresas deste estudo apresentam assistência médica, porém, nem todas oferecem assistência odontológica.

De acordo com nossos resultados foi encontrada elevada taxa de assistência odontológica (85,71\%), presente também em estudos onde 63,3\% das empresas ofereciam este benefício (CIRILO et al. ${ }^{12}$, 2002), distoando porém de outras pesquisas onde a taxa de assistência odontológica encontrada foi de 34,04\% (PIZZATO $\left.{ }^{58}, 2002\right)$, e em outros países que somente $16 \%$ das empresas mantinham essa assistência (SO e SCHWARZ $\left.^{66}, 1995\right)$.

Apesar da elevada taxa de assistência odontológica encontrada, dados sobre a saúde bucal dos trabalhadores ainda encontramse com índices elevados de doença (DINII ${ }^{16}$, 1995; PETERSEN e TANASE ${ }^{53}$, 1997; TOMITA et al. $\left.{ }^{70}, 1999 ;\right)$, refletindo assim, que são necessárias além do oferecimento da assistência, campanhas educativas que motivem o trabalhador para a busca e manutenção de níveis adequados de saúde.

O benefício quando oferecido se estende também à família do funcionário, como verificado neste e em outros estudos (WALDMAN ${ }^{73}, 1995$; PIZZATO $^{58}$, 2002) 
Mesmo sendo importante (ARAÚJO e JÚNIOR², 1999; MOTA e ALBUQUERQUE ${ }^{45}$, 1983) parece que as empresas não valorizam os exames odontológicos admissional, nem o periódico, pois ambos não são realizados por nenhuma das empresas pesquisadas.

Nos resultados encontrados, 0 tipo de assistência predominante foi convênio com $C D$ em consultório particular e uma associação entre o oferecimento de convênio em consultório particular fora da empresa e reembolso parcial do valor do tratamento, corroborando estudos anteriores onde as empresas também firmaram convênio com CD em consultório particular (CIRILO et al. $^{12}$, 2002), ou tercerizavam este serviço (PIZZATO $\left.{ }^{58}, 2002\right)$.

O alto percentual de empresas que oferecem benefício odontológico pode ser reflexo da preocupação com a satisfação, desempenho e saúde de seus funcionários.

\subsubsection{Saúde bucal do trabalhador}

Porém, com relação à saúde bucal dos trabalhadores, os índices ainda são desanimadores e reforçam a necessidade de ações preventivas e educativas que visem à melhoria dessas condições. 
O custo do tratamento odontológico é a razão mais freqüente para não visitar o cirurgião-dentista (SO; SCHWARZ ${ }^{67}$, 1996). Semelhantes informações foram dadas por funcionários que alegaram que o valor cobrado poderia ser reduzido.

A amostra de funcionários predominante masculina foi semelhante ao trabalho desenvolvido em outro tipo de indústria, porém que apresentavam as mesmas características de tipo de trabalho pesado (FERRAZ, BELINI $\left.{ }^{21}, 1983\right)$.

Os funcionários conheciam seus benefícios, diferentemente de estudo onde cerca de $40 \%$ não conheciam a cobertura dos benéficos da empresa (SO e SCHWARZ67, 1996).

Estudos anteriores mostraram que homens apresentam higiene pior comparada às mulheres $\left(A B E E G^{1}, 1997\right)$, mesmo assim, nesta pesquisa, o número de dentes presentes foi menor nas mulheres.

Certamente a empresa tem responsabilidade na preservação da saúde de seus funcionários, o que não exime o próprio indivíduo de buscar melhores condições de saúde e de vida. Portanto, a empresa deve sim facilitar o acesso ao tratamento odontológico. Porém, o trabalhador deve apresentar interesse, buscando atendimento e assumindo responsabilidade 
pela sua saúde. As ações conjuntas garantem melhores resultados (BRANT, $\left.\mathrm{MELO}^{7}, 2001\right)$.

A assistência odontológica para os trabalhadores é importante, porém seu simples oferecimento não é suficiente e não garante boa saúde para esta população, como julgávamos antes da realização deste estudo. Os resultados obtidos demonstram que $68 \%$ dos trabalhadores nunca utilizaram o convênio odontológico oferecido por uma das empresas.

É necessário portanto que o trabalhador tenha conhecimento dos benefícios que estão à sua disposição e faça uso dos mesmos. A assistência odontológica oferecida deve ser acessível não somente em termos de localização mas, principalmente relacionada aos custos, pois a grande parte dos funcionários da linha de produção apresentam baixos salários, Sendo assim, o ideal seria que a assistência odontológica fosse subsidiada integralmente pela empresa.

Por outro lado, quando existe serviço gratuito, são necessárias medidas educativas que orientem sobre a necessidade da manutenção da saúde bucal, para que não ocorra retornos ao consultório odontológico somente quando a doença já esta manifestada por meio de seus sinais e sintomas. Diante disto, afirma-se que manobras adicionais são necessárias no intuito de preservar e melhorar as condições de saúde bucal dos trabalhadores. 
A proposição de metas mundiais oferece referências para comparações internacionais, porém é importante avaliar as metas de forma coerente com a realidade local para que possam ser orientadas mais adequadamente as ações de planejamento, execução e avaliação dos serviços.

No que diz respeito a condição de dentes presentes na cavidade bucal, as metas da OMS para o ano de 2000 , era que $75 \%$ dos indivíduos na faixa etária de 35 a 44 anos, apresentassem 20 ou mais dentes na boca e para o ano de 2010, 90\%. Dados do Brasil (MINISTÉRIO DA SAÚDE ${ }^{43}$, 2004) demonstraram que a meta não foi atingida, pois somente $53,96 \%$ destas pessoas apresentavam essa quantidade de dentes. Nossos resultados apesar de se aproximarem mais, ainda não atingiram o esperado, cerca de $70 \%$ dos trabalhadores de grandes empresas apresentam 20 ou mais dentes na cavidade bucal.

Possivelmente a preservação de dentes funcionais na cavidade bucal mantenha relação com indicadores sócio-econômicos como demonstra estudo anterior. (FRAZÃO, ANTUNES, NARVAI ${ }^{25}, 2003$ )

Devido a perda de dentes, a grande maioria dos adultos faz uso ou necessita de próteses, portanto este estudo assim como outros (DINI $^{16}$, 1995; DOUGHAN, KASSAK, BOURGEOIS ${ }^{17}$, 2000; MINISTÉRIO DA 
SAÚDE $\left.{ }^{43}, 2004 ;\right)$ observou a condição de saúde bucal, uso e necessidade de prótese que os trabalhadores apresentavam.

Com relação ao uso de prótese, como observado em levantamento realizado no país, é mais freqüente o uso na arcada superior (37\%) comparada à inferior (12\%). Justamente por razões estéticas, se torna mais aceitável a ausência de dentes inferiores. A necessidade maior recai sobre o uso de prótese com múltiplos elementos tanto para a arcada superior quanto para a inferior.

Comparando o uso de prótese em relação ao gênero (Tabela 6 e 7), as mulheres utilizam mais próteses do que os homens, possivelmente por estas apresentarem desde a infância um índice CPOD maior, associado a uma exigência feminina de estética favorável.

É importante ressaltar que os dados aqui discutidos são referentes a empresas de grande porte, onde normalmente existem mais benefícios e cuidados em relação à saúde do trabalhador. Em pequenas e médias empresas a condição de assistência à saúde e a própria condição de saúde dos trabalhadores devem se apresentar piores.

A assistência odontológica é importante, porém para que os índices possam melhorar, ações de atenção à Saúde Bucal do Trabalhador 
devem ser desenvolvidas. É necessária ação preventiva e educativa visando desenvolver a motivação necessária para o cuidado com a saúde.

A odontologia deve fazer parte das preocupações com a Saúde do Trabalhador, é preciso integrá-la às demais áreas, buscando melhores condições de saúde àqueles que movem a sociedade com sua força de trabalho (MIDORIKAWA $\left.{ }^{40}, 2000\right)$. 
7 CONCLUSÃO 


\section{CONCLUSÃO}

Após a realização deste estudo e análise dos dados obtidos conclui-se que:

A assistência odontológica para os funcionários é uma preocupação dentro das empresas de grande porte, e é oferecida como benefício por $85,71 \%$ das empresas pesquisadas da DIR X.

O tipo de assistência oferecida predominante foi convênio com CD em consultório particular (33,33\%) e uma associação entre oferecimento de convênio em consultório particular e reembolso parcial do valor do tratamento $(33,33 \%)$.

Com relação à saúde bucal, o resultado encontrado em trabalhadores, da linha de produção com faixa etária de 35 a 44 anos, se apresentou próximo da meta da Organização Mundial de Saúde. Pois 70\% destes apresentavam 20 ou mais dentes na cavidade bucal, sendo que a meta para o ano 2000 era encontrar pelo menos $75 \%$ dos dentes na cavidade bucal.

Em uma empresa onde existe assistência odontológica com consultório próprio e CD prestador de serviço, a maioria dos funcionários (68\%) nunca utilizou o benefício e $62 \%$ reduziriam o custo dos tratamentos. 
ANEXXS 
ANEXO 1 - Dados SB- Brasil.

TABELA - Número e \% de indivíduos de 35 a 44 anos, que usam prótese segundo o tipo de prótese dentária. Brasil, 2003.

\begin{tabular}{cc|c|c|c}
\hline & \multicolumn{2}{c}{ Superior } & Inferior \\
\cline { 2 - 5 } & $N$ & $\%$ & 11.295 & $\%$ \\
\hline NÃO USA & 6.911 & 51,69 & 2.077 & 13,75 \\
\hline USA & 6.458 & 48,31 & 124 & 0,82 \\
\hline PF & 427 & 3,19 & 93 & 0,62 \\
\hline de 1 PF & 194 & 1,45 & 832 & 5,51 \\
\hline PPR & 2.227 & 16,66 & 81 & 0,54 \\
\hline de 1 PPR & 196 & 1,47 & 947 & 6,27 \\
\hline PT & 3.414 & 25,54 & 13.372 & 100,00 \\
\hline
\end{tabular}


ANEXO 2 - Dados SB-Brasil.

TABELA - Número e porcentagem de indivíduos que necessitam prótese segundo tipo de prótese dentária. Brasil, 2003.

\begin{tabular}{|c|c|c|c|c|}
\hline & \multicolumn{2}{|c|}{ Superior } & \multicolumn{2}{|c|}{ Inferior } \\
\hline & $\mathrm{N}$ & $\%$ & $\mathrm{~N}$ & $\%$ \\
\hline NÃO NECESSITA & 8.576 & 64,17 & 3.877 & 29,01 \\
\hline NECESSITA & 4.789 & 35,83 & 9.498 & 70,99 \\
\hline $\begin{array}{l}1 \text { PF ou PPR } \\
\text { (1 elemento) }\end{array}$ & 836 & 6,26 & 935 & 7,00 \\
\hline $\begin{array}{c}1 \text { PF ou PPR } \\
\text { (+ de } 1 \text { elemento) }\end{array}$ & 1.717 & 12,85 & 3.829 & 28,65 \\
\hline $\begin{array}{c}\text { Combinação de } \\
\text { Próteses }\end{array}$ & 1.899 & 14,21 & 4.340 & 32,47 \\
\hline PT & 337 & 2,52 & 385 & 2,88 \\
\hline Total & 13.365 & 100,00 & 13.366 & 100 \\
\hline
\end{tabular}




\section{Universidade de São Paulo Faculdade de Odontologia de Bauru \\ Al. Dr. Oetaivio Pinheiro Brisolla, 9-75 - Bauru-SP - CEP 17012-901 - C.P. 73 PABX (0XX14)3235-8000 - FAX (0XX14)3223-4679 \\ Comile de Éfica em Pesquisa}

Processo $n^{*} 37 / 2004$

Bauru, 05 de abril de 2004 .

Senhor Professor,

O projeto de pesquisa encaminhado a este Comitê de Ética em Pesquisa em Seres Humanos, denominado "Saúde bucal do trabalhador e a assistência odontológica nas empresas", de autoria de Lucilene Sanches Cirilo da Cunha, que será deșenvolvido sob sua orientaçăo, foi enviado ao relator para avaliaçăo.

Na reuniẫo de 31 de março de 2004 o parecer do relator, aprovando o projeto, foi aceito pelo Comitê, considerando que não existem infraçōes éticas pendentes

Informamos que após o envio do trabalho concluido, este Comitê enviarà o parecer final, que será utilizado para publicaçalo do trabalho.

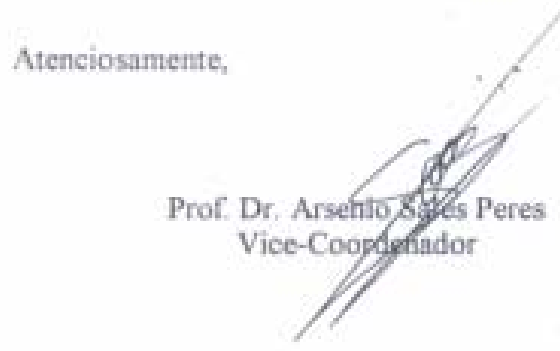

$1 \mathrm{~m} \mathrm{~m}^{\circ}$ Sr. Prof. Dr. José Roberto Pereira Lauris

DD. Docente do Departamento de Odontopediatria, Ortodontia e Saúde Coletiva 


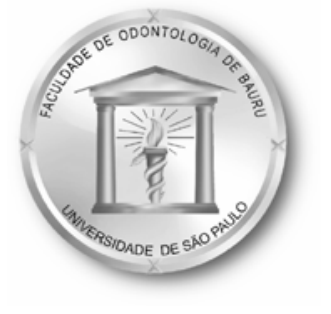

\author{
Universidade de São Paulo \\ Faculdade de Odontologia de Bauru \\ DEPARTAMENTO DE ODONTOPEDIATRIA, ORTODONTIA E \\ SAÚDE COLETIVA \\ Al. Dr. Octávio Pinheiro Brisolla, 9-75 - Bauru-SP - CEP:17043-101 \\ C.P. 73 - PABX: (014) 235-8000 - FAX: (014) 3223-4679
}

\title{
CARTA DE INFORMAÇÃO (empresa)
}

Este estudo tem como objetivo analisar a existência e o tipo de assistência odontológica oferecida por empresa de grande porte, verificar o uso e satisfação do funcionário diante do benefício oferecido e sua condição de Saúde Bucal. Sua participação será através da resposta ao questionário que faz parte do material de Dissertação de Mestrado, que tem como título Saúde Bucal do trabalhador e a assistência odontológica nas empresas. As informações obtidas através desta pesquisa estarão protegidas por sigilo profissional, e enviadas para as empresas participantes assim como a análise dos dados será publicada em revista especializada, certamente preservando a identidade da empresa.Caso a empresa queira apresentar reclamações em relação a sua participação na pesquisa, poderá entrar em contato com o Comitê de Ética em Pesquisa em Seres Humanos, da FOB-USP, pelo endereço da Al. Dr. Octávio Pinheiro Brisolla, 9-75 (sala no prédio da Biblioteca, FOB/USP) ou pelo telefone (14)235-8356.

\footnotetext{
TERMO DE CONSENTIMENTO LIVRE E ESCLARECIDO

Pelo presente instrumento que atende às exigências legais, o senhor(a)__ portador de documento de identidade número $(\mathrm{RG}) \_$_ após leitura minuciosa da CARTA DE INFORMAÇÃO explicada pelos profissionais em seus mínimos detalhes, ciente do procedimento (entrevista baseada em questionário) ao qual será submetido, não restando quaisquer dúvidas à respeito do lido e explicado, firma seu CONSENTIMENTO LIVRE E ESCLARECIDO, concordandoem participar da pesquisa proposta.

Fica claro que o participante da pesquisa pode, a qualquer momento, retirar seu consentimento e deixar de participar dessa pesquisa e ciente de que todas as informações prestadas tornaram-se confidenciais e guardadas por força de sigilo profissional (art. $9^{\circ}$ do Código de Ética Odontológica).

Por estarem de acordo, assinam o presente termo.
}

Bauru-SP,_de____ de 2004.

assinatura do participante

Lucilene Sanches Cirilo da Cunha

mestranda 
ANEXO 5

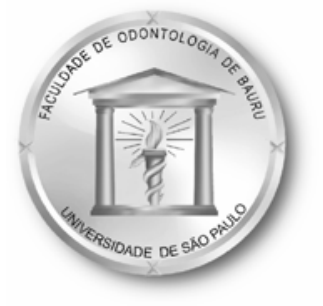

\author{
Universidade de São Paulo \\ Faculdade de Odontologia de Bauru \\ DEPARTAMENTO DE ODONTOPEDIATRIA, ORTODONTIA E \\ SAÚDE COLETIVA \\ Al. Dr. Octávio Pinheiro Brisolla, 9-75 - Bauru-SP - CEP:17043-101 \\ C.P. 73 - PABX: (014) 235-8000 - FAX: (014) 3223-4679
}

\title{
CARTA DE INFORMAÇÃO (funcionário)
}

Este estudo tem como objetivo analisar a existência e o tipo de assistência odontológica oferecida por empresa de grande porte, verificar o uso e satisfação do funcionário diante do benefício oferecido e sua condição de Saúde Bucal. Sua participação será feita através da resposta ao questionário que faz parte do material de Dissertação de Mestrado, que tem como título Saúde Bucal do trabalhador e a assistência odontológica nas empresas. Será realizado um exame de sua boca, não sendo feito nenhum tipo de tratamento apenas a contagem de quantos dentes o senhor(a) possui. As informações obtidas através desta pesquisa estarão protegidas por sigilo profissional, você não será identificado. A análise dos dados será publicada em revista especializada, certamente preservando a sua identidade e de sua empresa.

Caso você queira apresentar reclamações em relação a sua participação na pesquisa, poderá entrar em contato com o Comitê de Ética em Pesquisa em Seres Humanos, da FOB-USP, pelo endereço da Al. Dr. Octávio Pinheiro Brisolla, 9-75 (sala no prédio da Biblioteca, FOB/USP) ou pelo telefone (14)235-8356.

\footnotetext{
TERMO DE CONSENTIMENTO LIVRE E ESCLARECIDO

Pelo presente instrumento que atende às exigências legais, o senhor(a)_ portador de documento de identidade número $(\mathrm{RG}) \ldots$ _ após leitura minuciosa da CARTA DE INFORMAÇÃO explicada pelos profissionais em seus mínimos detalhes, ciente do procedimento (entrevista baseada em questionário) ao qual será submetido, não restando quaisquer dúvidas à respeito do lido e explicado, firma seu CONSENTIMENTO LIVRE E ESCLARECIDO, concordando em participar da pesquisa proposta.

Fica claro que o participante da pesquisa pode, a qualquer momento, retirar seu consentimento e deixar de participar dessa pesquisa e ciente de que todas as informações prestadas tornaram-se confidenciais e guardadas por força de sigilo profissional (art. $9^{\circ}$ do Código de Ética Odontológica).

Por estarem de acordo, assinam o presente termo.

Bauru-SP, de de 2004.
}

assinatura do participante

Lucilene Sanches Cirilo da Cunha

mestranda

Prof. Dr. José Roberto Pereira Lauris

Orientador 
ANEXO 6

Universidade de São Paulo

Faculdade de Odontologia de Bauru

DEPARTAMENTO DE ODONTOPEDIATRIA, ORTODONTIA E

SAÚDE COLETIVA

Al. Dr. Octávio Pinheiro Brisolla, 9-75 - Bauru-SP - CEP:17043-101

C.P. 73 - PABX: (014) 235-8000 - FAX: (014) 3223-4679

\section{QUESTIONÁRIO (empresa)}

1. Quais os benefícios oferecidos pela empresa aos seus funcionários?

convênio / assistência médica

convênio com farmácia

convênio / assistência odontológica

2. É feito exame odontológico admissional? sim não

3. Qual o tipo de assistência odontológica oferecida?

consultório odontológico próprio e CD contratado

consultório odontológico próprio e CD prestador de serviço

convênio com CD em consultório particular

convênio com Sistema de Saúde Odontológico (

reembolso do valor do tratamento (

outro

4. O benefício é concedido: apenas para o funcionário funcionário e familiares outro

5. Qual a estimativa de uso por parte dos funcionários?

6. Qual é o custo para o funcionário? E há quanto tempo é oferecida?

7. Existe atividade preventiva em Odontologia desenvolvida dentro da empresa? não sim:

8. Quantos dentistas participam do convênio?

9. Quais especialidades odontológicas estão incluídas?

10. O funcionário é chamado para exames bucais periódicos?

não sim Qual a periodicidade? 
Universidade de São Paulo

Faculdade de Odontologia de Bauru DEPARTAMENTO DE ODONTOPEDIATRIA, ORTODONTIA E

SAÚDE COLETIVA

Al. Dr. Octávio Pinheiro Brisolla, 9-75 - Bauru-SP - CEP:17043-

101

C.P. 73 - PABX: (014) 235-8000 - FAX: (014) 3223-4679

\section{QUESTIONÁRIO (funcionário)}

1. Quais os benefícios oferecidos pela empresa aos seus funcionários? convênio / assistência médica convênio com farmácia

convênio / assistência odontológica

Se a empresa possui assistência odontológica, responda:

2. Você utiliza os serviços odontológicos oferecidos pela empresa? $\operatorname{sim}$ não. E sua família utiliza? sim não

3. Se utiliza, com que freqüência?

quando sente dor de 6 em 6 meses quando a restauração quebra outro

4. Se não utiliza, qual a razão:

5. Você aprova este tipo de assistência? sim não

6. O que poderia melhorar?

7. Você já foi trabalhar mesmo sentindo dor de dente? sim não

8. Já faltou ao serviço por causa da dor de dente? $\operatorname{sim}$ não

9. Você é chamado pela empresa para realizar exame bucal? $\operatorname{sim}$ não 


\section{ANEXO 8}

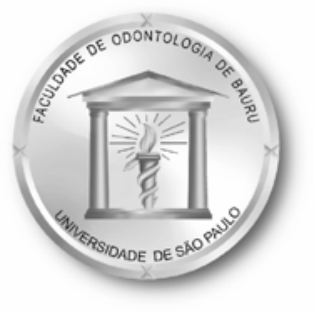

Universidade de São Paulo

Faculdade de Odontologia de Bauru

DEPARTAMENTO DE ODONTOPEDIATRIA, ORTODONTIA E

\section{SAÚDE COLETIVA}

Al. Dr. Octávio Pinheiro Brisolla, 9-75 - Bauru-SP - CEP:17043-101

C.P. 73 - PABX: (014) 235-8000 - FAX: (014) 3223-4679

FICHA DE AVALIAÇÃO DA SAÚDE BUCAL

INFORMAÇÕES GERAIS

Nome:

Empresa:

Data de nascimento Idade em anos Sexo

PRESENÇA DENTÁRIA

$\mathrm{A}$ - ausente $\mathrm{P}$ - presente

$\begin{array}{llllllllllllllll}18 & 17 & 16 & 15 & 14 & 13 & 12 & 11 & 21 & 22 & 23 & 24 & 25 & 26 & 27 & 28\end{array}$

Dente

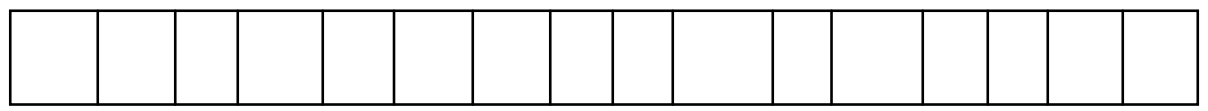

$\begin{array}{llllllllllllllll}48 & 47 & 46 & 45 & 44 & 43 & 42 & 41 & 31 & 32 & 33 & 34 & 35 & 36 & 37 & 38\end{array}$

Dente

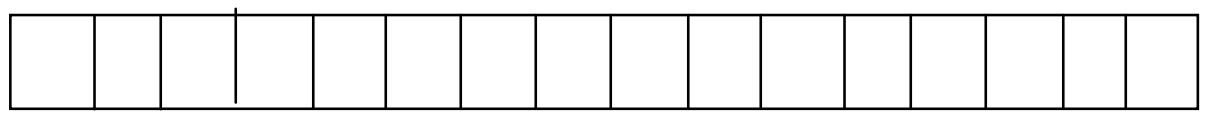

\section{CONDIÇÕES PROTÉTICAS}

$0=$ Sem prótese

$1=$ Prótese parcial fixa

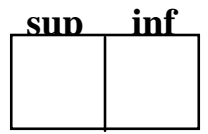

2 = Mais de uma prótese parcial fixa

3 = Prótese parcial removível

4 = Próteses parciais, fixas e removíveis

$5=$ Prótese total removível

$9=$ Não registrado

\section{NECESSIDADES PROTÉTICAS}

0 = Não necessita nenhuma prótese

1 = Necessita de prótese unitária

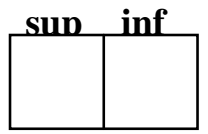

2 = Necessita de prótese com múltiplos elementos

3 = Necessita de uma associação de próteses unitárias e/ou com múltiplos elementos

4 = Necessita de prótese total

$9=$ Não registrado 
ANEXO 9 - Escovas dentárias distribuídas para os funcionários.

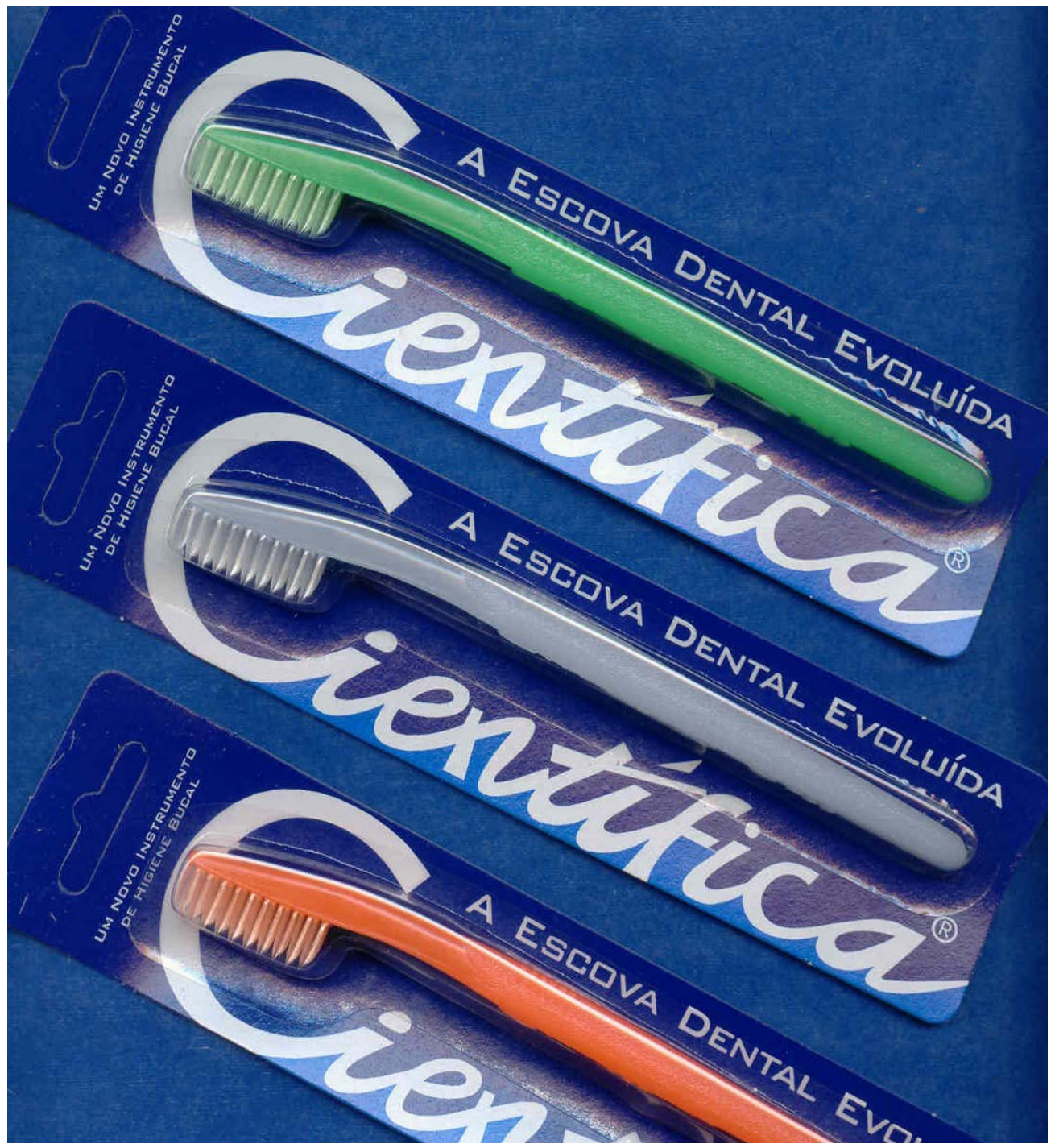


ANEXO 10 - Folheto distribuído para os funcionários.

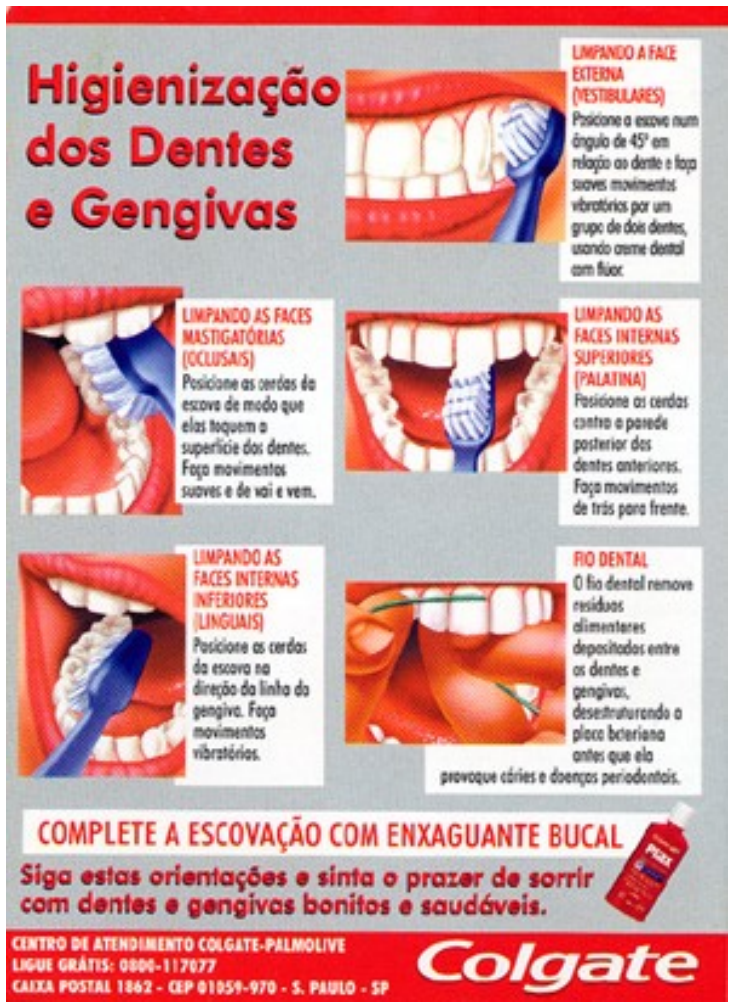

(frente)

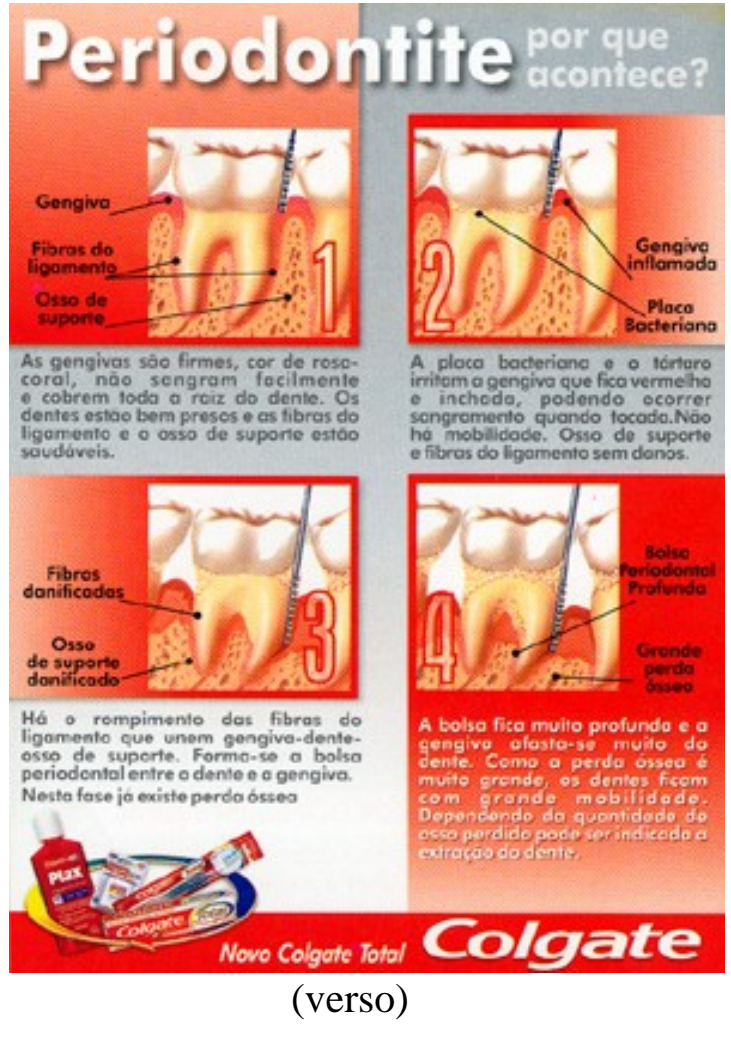


REFERÊTSCIAS BIBLIOGRÁFICAS 


\section{REFERÊNCIAS BIBLIOGRÁFICAS*}

1. ABEEG, C. Hábitos de higiene bucal de adultos porto-alegrenses. Rev Saúde Pública, v.31, n.6, p.586-93, dez., 1997.

2. AMIN, W.M.; AL-OMOUSH, S.A.; HATTAB, F.N. Oral health status of workers exposed to acid fumes in phosphate and battery industries in Jordan. Int. Dent. J., v.51, n.3, p. 169-74, 2001.

3. ARAÚJO, M.E.; JÚNIOR, G.A. Saúde bucal do trabalhador: os exames admissional e periódico como um sistema de informação em saúde. Odontol. Sociedade, v.1, n.1/2, p.15-8, 1999.

4. ASSIS, V. Odontologia do trabalho. Jornal do Cons. Fed. Odontol., $\mathrm{n}^{\circ}$ 61 e 62, jul/out. 2004.

5. ASSUNÇÃO, A.A. Uma contribuição ao debate sobre as relações saúde e trabalho. Ciência e Saúde Coletiva, v.8, n.4, p.1005-18, 2003.

6. BOTINO, M.A.; MOREIRA, E.J.G.; ROSSETINI, S.M.O. Estabelecimento de hábitos de higiene bucal em pacientes adultos. Rev. Ass. Paul. Cirurg. Dent., v.36, n.3, p.280-6, mai./jun. 1982.

\footnotetext{
* Normas recomendadas para uso no âmbito da Universidade de São Paulo, com base no documento "Referências Bibliográficas: exemplos”, emanado do Conselho Superior do Sistema de Bibliotecas da USP, em reunião de 20 de setembro de 1990.
} 
7. BRANT, L.C.; MELO, M.B. Promoção da saúde e trabalho: um desafio teórico e metodológico para a saúde do trabalhador. Saúde em Debate, v.25, n.57, p.55-62, jan./abr. 2001.

8. BRASIL. Portaria no 1339 de 18 de novembro de 1999. Institui a Lista de Doenças relacionadas ao Trabalho. Diário Oficial da União, Brasília, p.21, 19 nov. 1999.

9. BRASIL, Conselho Federal de Odontologia. Resolução CFO 25/2002. Estabelece áreas de competência para atuação de especialistas e dá outras providências. Diário Oficial da União, Seção 1, 28/05, p.148-9, Brasília, 2002.

10. BRITO, V.J. Obrigatoriedade do exame odontológico. O Incisivo, v.3, p.13-4, 1964.

11. CANGUSSU, M.C.T.; COELHO, E.O.; CASTELHANOS FERNENDES, R.A. Condições de saúde bucal em adultos e idosos em Itatiba/SP, Brasil - 2000. Rev. Odontol. Unesp, v.30, n.2, p.245-56, jul.-dez. 2001.

12. CIRILO, L.S. et al. Análise da assistência odontológica prestada a funcionários de empresas em Bauru-SP-Brasil. Monografia HRAC Bauru, 2002. 
13. CONSELHO NACIONAL DE SAÚDE. Resolução 196 de 10 de outubro de $1996 . \quad$ Disponível na Internet: http://www.conselho.saude.gov.br/docs/Reso196.doc em 10 de janeiro de 2004.

14. DePORTER, D.J. The future of dental benefits. J. Am. Coll. Dent., v.64, n.3, p.10-2, Fall 1997.

15. DIACOV, N.; SÁ LIMA, J.R. Absenteísmo odontológico. Rev Odontol Unesp, v.17, n.1/2, p.183-9, 1988.

16. DINI, E.L. Uso de prótese dental, índice de placa e condições periodontais. Rev Odontol UNESP, v.24, n.1, p.161-7, jan./jun. 1995.

17. DOUGHAN, B.; KASSAK, K.; BOURGEOIS, D.M. Oral health status and treatment needs of 35-44 year old adults in Lebanon. Int. Dent. J., v.50, n.6, p.395-9, 2000.

18.DUNNING, J.M.; WALLS, R.M.; LEWIS, S.R. Prevalence and characteristics of dental service in industry. J Am Dent Assoc, v.28, p.492-501, mar. 1941.

19. ESTEVES, R.C. Manifestações bucais de doenças profissionais. Rev Bras Saúde Ocupac, v.10, n.40, p.56-8, out./dez. 1982. 
20.FEDERATION DENTAIRE INTERNACIONALE Global goal for oral health in the year 2000. Int, Dent. J., v.32, n.1, p.74-7, 1982.

21. FERRAZ, C.; BELINI, H.T. Condições dentárias de um grupo de trabalhadores adultos em Jundiaí (SP). Rev Assoc Paul Cirurg Dent, v.37, n.4, p.330-5, jul./ago. 1983.

22. FERREIRA, R.A. O valor da saúde bucal nas empresas. Rev Assoc Paul Cir Dent, v. 49, n.2, p.96-107, mar./abr. 1995.

23. FERREIRA, R.A. Odontologia: essencial para a qualidade de vida. Rev Assoc Paul Cir Dent, v.51, n6, p.514-524, nov./dez. 1997.

24.FISHWICK, M.R.; ASHLEY, F.P.; WILSON, R.F. Can a workplace preventive programme affect periodontal health? Brit Dent J, v.184, n.6, p.290-3, March 1998.

25. FRAZÃO, P.; ANTUNES, J.L.F.; NARVAI, P.C. Perda dentária precoce em adultos de 35 a 44 anos de idade. Estado de São Paulo, Brasil, 1998. Rev Bras Epidemiol., v.6, n.1, p.49-57, abr. 2003.

26. GARCIA, P.P.N.S. et al. Avaliação clínica do comportamento de higiene bucal em adultos. Re Odontol. UNESP, v.30, n.2, p.161-71, 2001. 
27. GARRAFA, V. Odontologia do trabalho. Rev Gaúcha Odontol, v.34, n.6, p. 508-12, nov./dez. 1986.

28. GOMES, E.B.; MAGALHÃES, H. Censo bucal na empresa sua importância no planejamento da assistência odontológica. Odont Mod., v.7, n.3, p.31-8, mar. 1980.

29. GUIMARÃES, E.; ROCHA, A.A. Odontologia do trabalho $-1^{\text {a }}$ parte Organização dos serviços de uma empresa. Odontól mod, v.7, p.712, jul. 1979.

30. GUIMARÃES, E.; ROCHA, A.A. Odontologia do trabalho - $2^{\mathrm{a}}$ parte Organização dos serviços de uma empresa. Odontól mod, v.7, n.8, p.23-6, ago. 1979.

31. GUIMARÃES, E.; ROCHA, A.A. Odontologia do trabalho - $3^{a}$ parte Organização dos serviços de uma empresa. Odont mod, v.6, n.9, p.40-50, set. 1979 .

32. HOLLISTER, M.C.; WEINTRAUB, J.A. The association of oral status with systemic health, quality of life, and economic productivity. J Dent Educ., v.57, n.12, p.901-12, Dez. 1993. 
33. IDE, R. et al. Evaluation of oral health promotion in the workplace: the effects on dental care costs and frequency of dental visits. Comm. Dent. Oral Epidemiol., v.29, p.213-9, 2001.

34. MASSALIN, K.E.; MURTOMAA, H.T.; SIPILÃ, K.P.J. Dental caries risk in relation to dietary habits and dental services in two industrial populations. J Public Health Dent., v.54, n.3, p.160-6, Summer, 1994.

35. MATOS, D.L. et al. Projeto Bambuí: avaliação de serviços odontológicos privados, públicos e de sindicato. Re Saúde Pública, v.36, n.2, p.23743, 2002.

36. MEDEIROS, E.P.G. Conceito de odontologia do trabalho. O Incisivo, v.5, n.24, p.22-4, nov. 1966.

37. MEDEIROS, E.P.G.; BIJELLA, V.T. Bases para a organização de programas dentais para operários. Rev Bras Odontol, v.27, n.166, p.303-11, nov./dez. 1970.

38. MEDEIROS, E.P.G.; BIJELLA, V.T. Aplicação racional da odontologia social no atendimento de operários. Rev Bras Odontol, v.22, n.172, p.276-80, nov./dez. 1971. 
39. MENDONÇA, T.C. Mutilação dentária: concepções de trabalhadores rurais sobre a responsabilidade pela perda dentária. Cad Saúde Pública, v.17, n.6, p.1545-7, nov./dez. 2001.

40. MIDORIKAWA, E.T. A Odontologia em saúde do trabalhador como uma nova especialidade profissional: definição do campo de atuação e funções do cirurgião-dentista na equipe de saúde do trabalhador. Dissertação de Mestrado. São Paulo: Faculdade de Odontologia da Universidade de São Paulo; 2000.

41. MILLER, Y.; LOCKER, D. Correlates of tooth loss in a Canadian adult population. J. Can. Dent. Assoc., v.60, n.6, p.549-55, 1994.

42. MINGUEZ, P. Gerenciando saúde bucal no ambiente de trabalho. Jornal do Cons Fed Odontol, n.61 e 62, p.4, jul/out. 2004.

43. MINISTÉRIO DA SAÚDE. Secretaria de atenção à saúde. Departamento de Atenção Básica. Coordenação Nacional de Saúde Bucal. Projeto SB Brasil 2003: Condições de saúde bucal da população brasileira 2002-2003 Resultados principais. Brasília 2004. Disponível na Internet:

http://www.cfo.org.br/dowload/relatorio SB brasil 2003.pdf,em 20/11/2004. 
44. MORISHITA, M.; SAKEMI, M.; TSUTSUMI, M. GAKE, S. Effectiveness of an oral health promotion programme at the workplace. $\mathbf{J}$ Oral Rehab., v.30, n.4, p. 414-17, Apr. 2003.

45. MOTTA, R.G.; ALBULQUERQUE, V.L.T. Organização e implantação do serviço odontológico em uma indústria mecânica S/A. Rev Bras Odontol, v.40, n.1, p.34-9, jan./fev. 1983.

46. MOTTA, R.; TOLEDO, V.L. Avaliação dos resultados de trabalho odontológico em uma indústria mecânica S.A. Rev Bras Odontol, v. 40, n.6, p.21-5, nov./dez. 1983.

47. NARVAI, P.C Odontologia e saúde bucal coletiva. São Paulo: Hucitec, 113p., 1994

48. NO AUTHORS LISTED. Dental components in prepaid health plans. Council on dental care programs. J Am Dent Assoc., v.101, n.5, p.817-20, Nov. 1980.

49. NOGUEIRA, D.P. Odontologia e saúde ocupacional. Rev Saúde Pública, v.6, n.2, p.211-23, jun. 1972.

50. NOGUERIRA, V.M.R.; PIRES, D.E.P. Direito à saúde: um convite à reflexão. Cad. Saúde Públ., v.20, n.3, p.753-760, mai.-jun. 2004. 
51. OLIVEIRA, M.H.B.; VASCONCELLOS, L.C.F. As políticas brasileiras de saúde do trabalhador: tempos de avaliação. Saúde em Debate, v.24, n.5, p.92-103, maio/ago., 2000.

52. ORGANIZAÇÃO MUNDIAL DE SAÚDE Levantamentos básicos em saúde bucal. São Paulo, Ed. Santos, 4ª ed. 1999.

53. PETERSEN, P.E.; DENMARK, C.; TANASE, M.; RAMANIA, B. Oral health status of an industrial population in Romania. Int. Dent. J., v.47, n.4, p.194-8, Aug. 1997

54.PETRY, P.C.; VICTORA, C.G.; SANTOS, I.S. Adultos livres de cárie: estudo de casos e controles sobre conhecimentos, atitudes e práticas preventivas. Cad Saúde Pública, v. 16, n.1, p. 145-53, jan.-mar. 2000.

55. PETTY, F.F. What is necessary to make industrial dentistry a credit to the dental profession? J. Am. Dent. Assoc., v.30, p.1418-27, 1943.

56. PINTO, V.G. Programação em Saúde Bucal. In: PINTO, V.G. Saúde Bucal Coletiva. São Paulo: Ed. Santos, p.116-9, 2000.

57. PIMENTEL, O.J.A. Odontologia do trabalho. Odont Mod, v.3, n.2, p. 989, mar./abr. 1976. 
58. PIZZATTO, E. A saúde bucal no contexto da saúde do trabalhador: análise dos modelos de atenção. Dissertação de Mestrado. Araçatuba; Faculdade de Odontologia da Universidade Estadual Paulista; 2002.

59.SÁ LIMA, J.R. Absenteísmo por causa odontológica - Análise comparativa entre funcionários da Prefeitura do Município de São José dos Campos e segurados do Instituto Nacional de Previdência Social - Inamps. Publicado em 29/10/2001. Disponível na Internet: http://www.odontologia.com.br/artigos.asp?id=22 em 19 de agosto de 2004.

60.SILVA, R.B.; SOUTO, D.F. Modelo de serviço assistencial em odontologia ocupacional $1^{\mathrm{a}}$ parte. Odont Mod, v.10, n.9, p.36-9, set. 1983.

61.SILVA, R.B.; SOUTO, D.F. Modelo de serviço assistencial em odontologia ocupacional $2^{\mathrm{a}}$ parte. Odont Mod., v.10, n.10, p.39-45, out. 1983.

62.SILVA, R.B.; SOUTO, D.F. Modelo de serviço assistencial em odontologia ocupacional $3^{\mathrm{a}}$ parte. Odontólogo Moderno, v.10, n.11/12, p.27-30, nov./dez. 1983. 
63.SILVA, Z.P.; BARRETO JUNIOR, I.F.; SANT'ANA, M.C. Saúde do trabalhador no âmbito municipal. São Paulo Perspect., v.17, n.1, p.47-57, jan.-mar. 2003.

64.SHIZUKUISHI, S. et al. Lifestyle and periodontal health status of Japanese factory workers. Ann. Period., v.3, n.1, p.303-4, July 1998.

65. SHOU, L. Oral Health promotion at worksites. Int Dent J, v.39, n.2, p.122-8, June 1989.

66. SO, F.H.C.; SCHWARZ, E. Prevalence and structure of dental benefit schemes in Hong Kong. Community Dental Health , v.12, n.1 p.12-7, Mar. 1995.

67.SO, F.H.C.; SCHWARZ, E. Demand for and utilization of dental services among Hong Kong employees with and without dental benefit coverage. Community Dent Oral Epidemiol, v.24, p.201-6, 1996.

68. STETZEL, M.R. Dental benefits. J. Ind. Dent. Assoc., v.79, n.3, p.89, Aut. 2000.

69. THOMAS, E.H. Mouth infection in industrial workers: a serious menace to general health; resultant loss to war production. JADA, v.30, n.15, p.1249-62, August 1943. 
70. TOMITA, N.E. et al. Saúde bucal dos trabalhadores de uma indústria alimentícia do centro-oeste paulista. Rev FOB, v.7, n.1/2, p.67-71, jan./jun. 1999.

71. TOMITA, N.E.; BASTOS, J.R.M.; BASSANI, A.C. Saúde bucal para todos! Viabilidade ou sonho? Odontol Capixaba, v.20, n.21, p.40-1, 1992.

72. VIANNA, M.I.P.; SANTANA, V.S. Exposição ocupacional a névoas ácidas e alterações bucais: uma revisão. Cad. Saúde Pública, v.17, n.6, p.1335-1344, nov.-dez. 2001.

73. WALDMAN, H.B. Dental insurance coverage for employees of small and large companies. Illinois Dental Journal, v.64, n.1, p. 17-20, Jan./Feb. 1995.

74. WESTERMAN, B. A preventive dental care programme at the workplace. Aust Dent J., v.38, n.3, p.215-5, June 1993.

75.ZATS, M.; LANDAY, M.; LEDELL, J.D. Dental benefits and reimbursements. Dent. Clin. North Am., v.31, p.193-207, 1989. 
ABSTRACT 


\section{ABSTRACT}

The oral health attention should be directed to all age ranges and specific populations. It is easy to find preventive programs developed for children, pregnant women and elderly, yet few programs address the adult population. In an attempt to direct efforts to improve the oral health of workers, the present study was conducted to verify the existence and type of dental care provided by large companies at the central west region of the State of São Paulo (DIR X), besides verifying the oral health status of workers aged 35 to 44 years. The first stage comprised interview in the administrative sector of 17 companies. Then, oral health examinations were performed in 100 individuals of a company that agreed to participate in this stage. The results demonstrated that $85.71 \%$ of the companies surveyed offer dental care, predominantly by agreement with dental professionals in private practice associated to reimbursement of $50 \%$ of the value of treatment. The mean number of present teeth was 23.61 for males and 19.43 for females, being that nearly $70 \%$ presented 20 or more teeth in good conditions, approaching the WHO goal for the year 2000. It was concluded that the dental care provided to workers is offered as a benefit by most companies of DIR X. Programs directed to improvement of the oral health status of workers are required, to allow achievement of levels compatible with the goals established by the World Health Organization. 